\title{
The importance of micrometeorological variations for photosynthesis and transpiration in a boreal coniferous forest
}

\author{
G. Schurgers ${ }^{1,2}$, F. Lagergren ${ }^{1}$, M. Mölder ${ }^{1}$, and A. Lindroth ${ }^{1}$ \\ ${ }^{1}$ Lund University, Dept. of Physical Geography and Ecosystem Science, Lund, Sweden \\ ${ }^{2}$ now at: University of Copenhagen, Dept. of Geosciences and Natural Resource Management, Copenhagen, Denmark \\ Correspondence to: G. Schurgers (gusc@ign.ku.dk)
}

Received: 1 August 2014 - Published in Biogeosciences Discuss.: 21 August 2014

Revised: 4 December 2014 - Accepted: 8 December 2014 - Published: 14 January 2015

\begin{abstract}
Plant canopies affect the canopy micrometeorology, and thereby alter canopy exchange processes. For the simulation of these exchange processes on a regional or global scale, large-scale vegetation models often assume homogeneous environmental conditions within the canopy. In this study, we address the importance of vertical variations in light, temperature, $\mathrm{CO}_{2}$ concentration and humidity within the canopy for fluxes of photosynthesis and transpiration of a boreal coniferous forest in central Sweden. A leaf-level photosynthesis-stomatal conductance model was used for aggregating these processes to canopy level while applying the within-canopy distributions of these driving variables.

The simulation model showed good agreement with eddy covariance-derived gross primary production (GPP) estimates on daily and annual timescales, and showed a reasonable agreement between transpiration and observed $\mathrm{H}_{2} \mathrm{O}$ fluxes, where discrepancies are largely attributable to a lack of forest floor evaporation in the model. Simulations in which vertical heterogeneity was artificially suppressed revealed that the vertical distribution of light is the driver of vertical heterogeneity. Despite large differences between abovecanopy and within-canopy humidity, and despite large gradients in $\mathrm{CO}_{2}$ concentration during early morning hours after nights with stable conditions, neither humidity nor $\mathrm{CO}_{2}$ played an important role for vertical heterogeneity of photosynthesis and transpiration.
\end{abstract}

\section{Introduction}

Plant canopies intercept radiation and alter the circulation of air and the exchange of energy at the land surface. The biochemical processes taking place in the plants and the soil affect the chemical composition of the air within the canopy. These biogeophysical and biogeochemical alterations made to the local environment in turn affect the canopy's biochemistry and exchange processes, and thereby provide a feedback to the growth of the canopy itself.

The extinction of light in the canopy results in a large gradient of light conditions within the canopy, and the differences get even more pronounced when considering shading, resulting in a directly lit leaf area and a leaf area that is shaded (e.g. Cowan, 1968; Norman, 1975). Within-canopy gradients of $\mathrm{CO}_{2}$ have been measured exceeding $50 \mathrm{ppm}$ (e.g. Buchmann et al., 1996; Brooks et al., 1997; Han et al., 2003). Moreover, forest canopies alter the temperature and humidity inside (Arx et al., 2012), with, in general, more moderate temporal variations within the canopy compared to the above-canopy environment.

Some of these types of heterogeneity have been captured in stand-scale models: for light extinction, a layering of the canopy can be applied (e.g. Monteith, 1965; Duncan et al., 1967; Cowan, 1968; Norman, 1975), as well as a separation of sunlit and shaded leaves (e.g. Duncan et al., 1967; Spitters, 1986). Model studies have been performed investigating the importance of forest structures for exchange processes (Ellsworth and Reich, 1993; Falge et al., 1997).

The Farquhar model (Farquhar et al., 1980) and models based on that (e.g. Leuning, 1990; Collatz et al., 1991), which describe leaf-level $\mathrm{CO}_{2}$ assimilation, form 
the basis of many canopy-scale photosynthesis models. Similarly, leaf-level stomatal conductance models (e.g. Ball et al., 1987; Leuning, 1995) have been applied on a canopy scale. For these canopy-scale applications, homogeneous conditions within the canopy are often assumed. This simplification has a great advantage for the simulation of the exchange processes: the canopy can be treated as a single big leaf (the so-called "big-leaf approach"; Sinclair et al., 1976; Sellers et al., 1992), and the upscaling from leaf-level process rates to a canopy-integrated rate can be done linearly by using the leaf area index of the canopy.

Although dynamic vegetation models typically apply leafscale models to describe the processes on the canopy scale, they vary greatly in the level of detail that they use to represent light extinction. The big-leaf approach described above is adopted by some dynamic vegetation models (e.g.: LPJ, Sitch et al., 2003; or Sheffield-DGVM, Woodward and Lomas, 2004). Other dynamic vegetation models, or land surface schemes within climate or Earth system models, include a layering (e.g.: O-CN, Zaehle and Friend, 2010; or SEIBDGVM, Sato et al., 2007). In addition to a vertical layering, Mercado et al. (2009) applied a distinction between sunlit and shaded leaves as well in the JULES land surface scheme. The layering described above is applied to determine light extinction; none of the large-scale models applies vertical gradients of humidity or $\mathrm{CO}_{2}$ concentration.

The assumption of homogeneous conditions within the canopy warrants a critical assessment: the possible gradients under canopy conditions, as mentioned above, have the potential to affect leaf photosynthesis and transpiration, and thereby cause deviations from this linear relationship, which affects the canopy-integrated values. In this study, we quantify the importance of vertical heterogeneity in environmental drivers on the leaf scale for the simulation of stand-scale fluxes of photosynthesis and transpiration for a coniferous forest in central Sweden for 1999. Within-canopy profile measurements were used to determine the heterogeneity in driving variables (temperature, ambient $\mathrm{CO}_{2}$ concentration, water vapour concentration and wind speed), and a detailed light transfer model was applied to compute the distribution of photosynthetic absorbed radiation (PAR). In the first part of the study, model results are compared with observations. In the second part, model simulations are described applying average within-canopy or above-canopy conditions instead of distributions, in order to assess the importance of heterogeneity for simulated GPP and transpiration. The importance of within-canopy variability is compared with the variability caused by diurnal and annual changes in driving variables.

\section{Materials and methods}

This study applies observations from the Norunda forest site, a coniferous forest in central Sweden, $60^{\circ} 05^{\prime} 11^{\prime \prime} \mathrm{N}$, $17^{\circ} 28^{\prime} 46^{\prime \prime} \mathrm{E}$, altitude $45 \mathrm{~m}$. The site is situated on a sandy glacial till; the long-term mean annual temperature is $5.5^{\circ} \mathrm{C}$ and annual precipitation is $527 \mathrm{~mm} \mathrm{yr}^{-1}$ (Lundin et al., 1999). The forest is dominated by Scots pine (Pinus sylvestris) and Norway spruce (Picea abies) with occasional broadleaf trees; the canopy is approximately $25 \mathrm{~m}$ high and has a leaf area index (LAI) of 4.5. More details about the site are found in Lundin et al. (1999).

For this site, a detailed photosynthesis-stomatal conductance model was applied to simulate canopy-scale photosynthesis and transpiration rates for 1999-2002. Simulated fluxes were compared with the fluxes of $\mathrm{CO}_{2}$ and $\mathrm{H}_{2} \mathrm{O}$ measured with eddy covariance. The simulations for 1999 were analysed further to address the importance of within-canopy heterogeneity in the simulations.

\subsection{Measurements}

\subsubsection{Canopy profile measurements}

Profile measurements of $\mathrm{CO}_{2}$ and water vapour concentrations, as well as air temperature and wind speed, were performed at a number of levels within and above the canopy. In this study we used the measurements within the canopy, as well as the first measurement above, to derive the profile of these properties within the canopy. The measurements from 8.5, 13.5, 19.0, 24.5 and $28.0 \mathrm{~m}$ above the forest floor were used (Lundin et al., 1999; Mölder et al., 2000). In addition, the concentrations of water vapour were measured at $0.7 \mathrm{~m}$ above the forest floor as well. All concentrations were averaged to half-hourly means.

For the simulation of within-canopy conditions, these profiles were linearly interpolated to represent the conditions. The lowest measurement was considered representative of the part of the canopy between the forest floor and the lowest measurement height.

\subsubsection{Flux measurements of $\mathrm{H}_{2} \mathrm{O}$ and $\mathrm{CO}_{2}$}

Eddy covariance measurements of exchange of $\mathrm{CO}_{2}$ and $\mathrm{H}_{2} \mathrm{O}$ were made at a height of $35 \mathrm{~m}$ (approximately $10 \mathrm{~m}$ above the canopy) with a closed-path system (a LI-6262 gas analyser, LI-COR Inc. and a Gill R2 sonic anemometer, Gill Instruments) at a frequency of $10 \mathrm{~Hz}$. The highfrequency flux measurements were aggregated to $30 \mathrm{~min}$ averages. A detailed description of the eddy covariance setup and the flux calculations is given in Grelle and Lindroth (1996) and Grelle et al. (1999).

Stable conditions prevailing during nighttime can cause a build-up of $\mathrm{CO}_{2}$, and to a lesser extent $\mathrm{H}_{2} \mathrm{O}$, within the canopy (Goulden et al., 1996; Aubinet et al., 2005). This was observed for the Norunda site as well (Feigenwinter et al., 2010), and we corrected the flux measurements for this storage of $\mathrm{CO}_{2}$ and $\mathrm{H}_{2} \mathrm{O}$ within the canopy with the help of the profile measurements of $\mathrm{CO}_{2}$ and $\mathrm{H}_{2} \mathrm{O}$ concentrations (Baldocchi and Wilson, 2001). To do so, the profiles of $\mathrm{CO}_{2}$ and 
$\mathrm{H}_{2} \mathrm{O}$ below the sensor were interpolated between the observation levels for the $30 \mathrm{~min}$ interval before and after that of the observed fluxes. The difference between the integrated profiles for these two time periods, divided by the average time between the two $\left(60^{\prime}\right)$, was assumed as storage flux $F_{\text {stor }}$ for the given time interval $t$ :

$F_{\text {stor }, t}=\frac{\int_{0}^{h} c_{z, t+\Delta t} \mathrm{~d} z-\int_{0}^{h} c_{z, t-\Delta t} \mathrm{~d} z}{2 \Delta t}$,

in which $c_{z}$ is the concentration of $\mathrm{CO}_{2}$ or $\mathrm{H}_{2} \mathrm{O}$ at height $z$ (expressed here in $\mathrm{mol} \mathrm{m}^{-3}$ ), obtained from linear interpolation of the profile data, and $\Delta t$ is the time interval for the aggregated measurements $\left(30^{\prime}\right)$.

Estimates of gross primary production (GPP) were derived from the measured $\mathrm{CO}_{2}$ flux (net ecosystem exchange, $\mathrm{NEE}$ ) by subtracting ecosystem respiration. For this, the data were distributed in 5 day periods, and for each period, the temperature dependence of ecosystem respiration was computed according to Reichstein et al. (2005) with a function (Lloyd and Taylor, 1994) fitted through all nighttime fluxes within a 15 day window centered around the 5 day period of consideration. For some periods, nighttime respiration showed little or no sensitivity to temperature, leading to subtraction of (near-)constant respiration.

Periods with missing observations (either missing climate data for the forcing, or missing flux data for comparison) were omitted from the analysis.

Grelle (1997) showed that the flux footprint of the $35 \mathrm{~m}$ level was well within the homogeneous ca. 100 year old mixed pine/spruce forest surrounding the tower in all directions. Occasionally the nighttime flux footprint extended beyond the homogeneous part of the forest into younger stands, ca. 50 years old, but still consisting of mixed coniferous forest.

\subsubsection{Auxiliary measurements}

Apart from the within-canopy properties, above-canopy conditions were used. Photosynthetically active radiation (PAR) was measured with a LI-1905Z PAR sensor (LI-COR Inc.). Measurements of diffuse radiation were not available for the studied period, but measurements of diffuse radiation with a BF-3 sunshine sensor (Delta-T Devices Ltd) that started in 2004 were applied to derive a relationship between the fraction of diffuse radiation at the surface and the fraction of the top-of-atmosphere radiation that reached the surface (described below, Sect. 2.2.1).

In addition to the eddy covariance measurements of the $\mathrm{H}_{2} \mathrm{O}$ flux, which represents the canopy's evapotranspiration, measurements of tree transpiration were performed in 1999 for a nearby site (500 $\mathrm{m}$ distance) using the tissue heat balance technique (Čermák et al., 1973). The site is younger (approximately 50 years old) than the footprint of the tower, but climatological and hydrological conditions were similar to those in the footprint, and it has a similar species compo- sition and leaf area. Details of the sapflow measurements are given in Lagergren and Lindroth (2002).

\subsection{Model description}

\subsubsection{Light distribution}

Because within-canopy measurements for light interception did not exist for this site, and because an accurate representation of the light interception requires a considerably larger distribution than the measurements at certain heights in the canopy as done for the other forcing data, a detailed radiation transfer scheme was constructed to simulate light distribution (Appendix A), which was used to simulate the distribution of PAR within the canopy. The scheme uses existing theory on light extinction and reflection, while using the assumptions made in large-scale models. It separates vertical layers, and sunlit and shaded fractions of the leaves within these layers. Moreover, within each fraction and layer, the leaf angle distribution (assuming an isotropic or spherical distribution) is represented by a grid of azimuth and zenith angles. For each of the leaf orientations in the sunlit and shaded fractions within each of the layers, absorption, reflection and transmission are computed with a two-way scheme computing the downward and upward scattering within the canopy with an angular distribution. Based on the separation between sunlit and shaded leaf areas, it provides a probability density function of absorbed PAR for each of the layers. The scheme does not account for clumping of leaves, nor does it account for penumbral radiation. Details of the light distribution scheme are provided in Appendix A.

The light distribution model requires a separation between direct and diffuse light. Observations of the diffuse flux were not available for the study period, but observations of the diffuse and total shortwave fluxes were available for June 2004 till December 2010. The latter were used to reparameterise a relationship between the diffuse fraction $\left(f_{\text {dif }}\right.$, the ratio between diffuse and global radiation at the surface) and the fraction of the top-of-atmosphere flux that is transmitted through the atmosphere $\left(f_{\text {trans }}\right.$, the ratio between the global radiation at the surface and the global radiation at the top of the atmosphere), described by Spitters et al. (1986). The boundaries between the regimes in this relationship, which were originally derived for De Bilt (Netherlands), did not match the observations from the Norunda forest site. 
Table 1. Parameter values for the photosynthesis-stomatal conductance model.

\begin{tabular}{llrll}
\hline Parameter & Symbol & Value & Unit & Reference \\
\hline Maximum rate of electron transport at 298 K & $J_{\max }$ & $144 . \times 10^{-6}$ & $\mathrm{~mol} \mathrm{~m}^{-2} \mathrm{~s}^{-1}$ & Thum et al. (2008) \\
Maximum rate of Rubisco activity at 298 K & $V_{\mathrm{c}, \max }$ & $25.4 \times 10^{-6}$ & $\mathrm{~mol} \mathrm{~m}^{-2} \mathrm{~s}^{-1}$ & Thum et al. (2008) \\
Activation energy for electron transport & $E(J)$ & $88.0 \times 10^{3}$ & $\mathrm{~J} \mathrm{~mol}^{-1}$ & Thum et al. (2008) \\
Activation energy for Rubisco activity & $E\left(V_{c}\right)$ & $73.6 \times 10^{3}$ & $\mathrm{~J} \mathrm{~mol}^{-1}$ & Thum et al. (2008) \\
Empirical curvature factor & $\theta$ & 0.7 & & Von Caemmerer (2000) \\
\hline Slope in stomatal conductance equation & $k$ & 9.0 & & Collatz et al. (1991) \\
Intercept in stomatal conductance equation & $b$ & 0.01 & $\mathrm{~mol} \mathrm{~m}^{-2} \mathrm{~s}^{-1}$ & Collatz et al. (1991) \\
\hline
\end{tabular}

Therefore, the parameters describing these boundaries were optimised by maximising the coefficient of determination of the function using the data for 2004-2010 (Fig. 1), resulting in the following relationship:

$$
\begin{array}{ll}
f_{\text {dif }}=1 & \text { for } f_{\text {trans }}<0.27 \\
f_{\text {dif }}=1-18.3\left(f_{\text {trans }}-0.27\right)^{2} & \text { for } 0.27 \leq f_{\text {trans }}<0.33 \\
f_{\text {dif }}=1.67-2.20 f_{\text {trans }} & \text { for } 0.33 \leq f_{\text {trans }}<0.65 \\
f_{\text {dif }}=0.23 & \text { for } f_{\text {trans }} \geq 0.65
\end{array}
$$

Apart from the fraction of diffuse radiation, the model requires a distribution of the diffuse light over sky azimuth and zenith angles. For this, we applied a standard overcast sky (Monteith and Unsworth, 1990), which has no azimuthal preference for the light, for conditions under which all radiation is diffuse $\left(f_{\text {dif }}=1\right)$. For a high fraction of diffuse radiation $\left(0.8<f_{\text {dif }}<1\right)$, a skylight distribution representing translucent high clouds (Grant et al., 1996) was applied, which represents diffuse conditions, but which concentrates part of the skylight in the solar direction. For lower fractions of diffuse radiation $\left(f_{\text {dif }} \leq 0.8\right)$, a clear sky distribution (Harrison and Coombes, 1988) was adopted.

The detailed light extinction model (Appendix A) requires a distribution of the light between absorption, reflection and transmission at the leaf level. For this, the fractions $0.85,0.09$ and 0.06 were used, respectively, values provided by Ross (1975) for mean green leaves.

\subsubsection{Flux model}

A combined photosynthesis-stomatal conductance model was constructed, similar to the algorithms used in many large-scale ecosystem models (e.g. in ORCHIDEE; Krinner et al., 2005). The model combines a Farquhar-type photosynthesis model (Farquhar et al., 1980) with a Ball-Berry type stomatal conductance model (Ball et al., 1987). However, in contrast to typical large-scale models, we treat it here as a leaf-level model, and do the upscaling from leaf level to canopy level explicitly by accounting for the heterogeneity in environmental drivers within the canopy (see Sect. 2.1.1).

Leaf-level photosynthesis is simulated as the minimum of the Rubisco-limited $\mathrm{CO}_{2}$ assimilation rate $A_{c}$ and the elec-

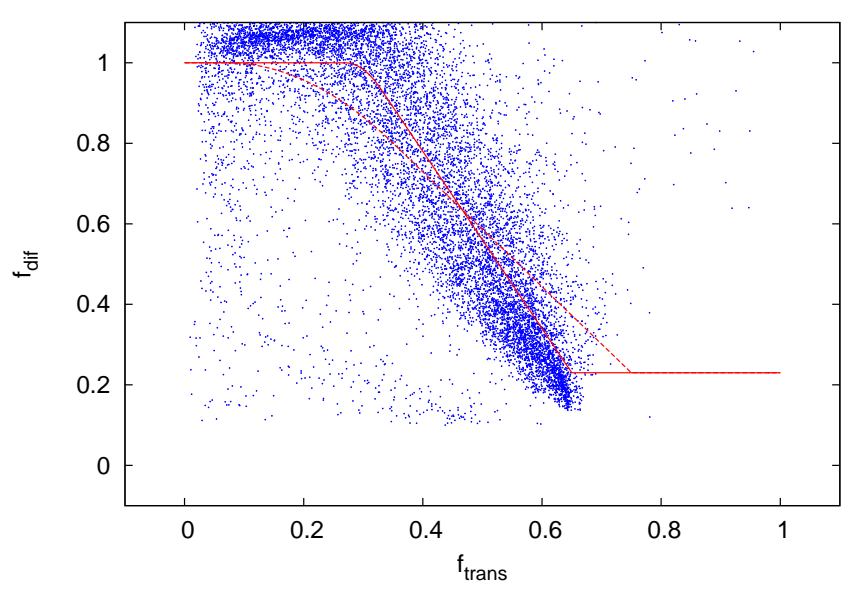

Figure 1. Relationship between the relative amount of incoming radiation at the surface (as a fraction of top-of-atmosphere radiation) $f_{\text {trans }}$ and diffuse fraction $f_{\text {dif }}$. Shown are data between June 2004 and December 2010. Data points with surface fractions $\leq 0$ or $>1$, as well as data points with diffuse fractions $<0.1$ or $>1.25$, were omitted. The original relationship by Spitters et al. (1986) (dashed, $R^{2}=0.61$ ) as well as the reparameterised relationship (full line, $\left.R^{2}=0.66\right)$ are displayed.

tron transport-limited $\mathrm{CO}_{2}$ assimilation rate $A_{\mathrm{j}}$ following Farquhar et al. (1980) and Von Caemmerer (2000):

$A=\min \left(A_{c}, A_{\mathrm{j}}\right)$

Because of the comparison with the NEE-derived photosynthesis flux, which has all respiration components subtracted, there is no accounting for the leaf's dark respiration in the computation of $A_{c}$ or $A_{\mathrm{j}}$.

The Rubisco-limited rate $A_{c}$ is simulated as a function of $\mathrm{CO}_{2}$ concentration and $\mathrm{O}_{2}$ concentration with temperaturedependent Michaelis-Menten constants for carboxylation and oxygenation (Von Caemmerer, 2000), and is dependent on the maximum Rubisco rate $V_{c, \max }$ (Table 1):

$$
A_{c}=\frac{\left(C_{i}-\Gamma_{*}\right) V_{c, \max }}{C_{i}+K_{c}\left(1+\frac{O}{K_{o}}\right)} .
$$

Here, $C_{i}$ is the leaf-internal $\mathrm{CO}_{2}$ concentration, $O$ is the leaf-internal $\mathrm{O}_{2}$ concentration (assumed constant at $21 \%$ ), 
Table 2. Overview of the simulations performed for this study.

\begin{tabular}{|c|c|c|c|c|c|}
\hline Abbreviation & Description & PAR & $\mathrm{CO}_{2}$ & Temperature & Humidity \\
\hline \multicolumn{6}{|l|}{ Reference simulation } \\
\hline HET & Full heterogeneity simulation & Profile & Profile & Profile & Profile \\
\hline \multicolumn{6}{|c|}{ Homogeneous conditions for one parameter } \\
\hline HOM_PAR & Homogeneous PAR & Canopy average & Profile & Profile & Profile \\
\hline HOM_PAR_LAYER & Profile, but homogeneous PAR within layer & Layer-averaged profile & Profile & Profile & Profile \\
\hline HOM_CO2 & Homogeneous $\mathrm{CO}_{2}$ (canopy average) & Profile & Canopy average & Profile & Profile \\
\hline HOM_CO2_AC & $\begin{array}{l}\text { Homogeneous } \mathrm{CO}_{2} \text { (above-canopy concen- } \\
\text { tration, } 28.0 \mathrm{~m} \text { ) }\end{array}$ & Profile & Above-canopy & Profile & Profile \\
\hline HOM_TEM & Homogeneous temperature & Profile & Profile & Above-canopy & Profile \\
\hline HOM_HUM & Homogeneous humidity & Profile & Profile & Profile & Canopy average \\
\hline HOM_HUM_AC & $\begin{array}{l}\text { Homogeneous humidity (above-canopy } \\
\text { concentration, } 28.0 \mathrm{~m} \text { ) }\end{array}$ & Profile & Profile & Profile & Above-canopy \\
\hline HOM_HUM_IC & $\begin{array}{l}\text { Homogeneous humidity (within-canopy } \\
\text { concentration, } 8.5 \mathrm{~m} \text { ) }\end{array}$ & Profile & Profile & Profile & Within-canopy \\
\hline \multicolumn{6}{|c|}{ Homogeneous conditions for all parameters except one } \\
\hline HET_PAR & Homogeneous in canopy except for PAR & Profile & Canopy average & Canopy average & Canopy average \\
\hline HET_CO2 & Homogeneous in canopy except for $\mathrm{CO}_{2}$ & Canopy average & Profile & Canopy average & Canopy average \\
\hline HET_TEM & $\begin{array}{l}\text { Homogeneous in canopy except for temper- } \\
\text { ature }\end{array}$ & Canopy average & Canopy average & Profile & Canopy average \\
\hline HET_HUM & $\begin{array}{l}\text { Homogeneous in canopy except for humid- } \\
\text { ity }\end{array}$ & Canopy average & Canopy average & Canopy average & Profile \\
\hline \multicolumn{6}{|c|}{ Diurnally averaged conditions for all parameters except one } \\
\hline DHET_PAR & $\begin{array}{l}\text { Homogeneous in diurnal cycle except for } \\
\text { PAR }\end{array}$ & Profile & Diurnally averaged profile & Diurnally averaged profile & Diurnally averaged profile \\
\hline DHET_CO2 & $\begin{array}{l}\text { Homogeneous in diurnal cycle except for } \\
\mathrm{CO}_{2}\end{array}$ & Diurnally averaged profile & Profile & Diurnally averaged profile & Diurnally averaged profile \\
\hline DHET_TEM & $\begin{array}{l}\text { Homogeneous in diurnal cycle except for } \\
\text { temperature }\end{array}$ & Diurnally averaged profile & Diurnally averaged profile & Profile & Diurnally averaged profile \\
\hline DHET_HUM & $\begin{array}{l}\text { Homogeneous in diurnal cycle except for } \\
\text { humidity }\end{array}$ & Diurnally averaged profile & Diurnally averaged profile & Diurnally averaged profile & Profile \\
\hline \multicolumn{6}{|c|}{ Annually averaged conditions for all parameters except one } \\
\hline AHET_PAR & $\begin{array}{l}\text { Homogeneous in annual cycle except for } \\
\text { PAR }\end{array}$ & Profile & Annually averaged profile & Annually averaged profile & Annually averaged profile \\
\hline AHET_CO2 & $\begin{array}{l}\text { Homogeneous in annual cycle except for } \\
\mathrm{CO}_{2}\end{array}$ & Annually averaged profile & Profile & Annually averaged profile & Annually averaged profile \\
\hline AHET_TEM & $\begin{array}{l}\text { Homogeneous in annual cycle except for } \\
\text { temperature }\end{array}$ & Annually averaged profile & Annually averaged profile & Profile & Annually averaged profile \\
\hline AHET_HUM & $\begin{array}{l}\text { Homogeneous in annual cycle except for } \\
\text { humidity }\end{array}$ & Annually averaged profile & Annually averaged profile & Annually averaged profile & Profile \\
\hline
\end{tabular}

$\Gamma_{*}$ is the $\mathrm{CO}_{2}$ compensation point, and $K_{c}$ and $K_{o}$ are the Michaelis-Menten constants for carboxylation and oxygenation, respectively, which are temperature dependent (Von Caemmerer, 2000). The electron transport-limited $\mathrm{CO}_{2}$ assimilation rate $A_{j}$ depends primarily on the electron transport rate $J$ at the leaf level, as well as on the leaf-internal $\mathrm{CO}_{2}$ concentration (Von Caemmerer, 2000):

$A_{\mathrm{j}}=\frac{\left(C_{i}-\Gamma_{*}\right) J}{4 C_{i}+8 \Gamma_{*}}$.

The electron transport rate $J$ is determined from the empirical function describing $J$ as a function of the absorbed irradiance $I$ (corrected for spectral quality and leaf absorbance) and the maximum electron transport rate $J_{\max }$ (Table 1), applying an empirical curvature factor $\theta$ (Farquhar et al., 1980; Von Caemmerer, 2000):

$J=\frac{I+J_{\max }-\sqrt{\left(I+J_{\max }\right)^{2}-4 \theta I J_{\max }}}{2 \theta}$.
The photosynthetic parameters determined by Thum et al. (2008), who used stand-scale eddy covariance measurements from Norunda for 2001 to parameterise their model, were adopted (Table 1).

Leaf-level stomatal conductance, $g_{\mathrm{s}}$, is simulated following Ball et al. (1987) with a modification by Collatz et al. (1991) as a function of the $\mathrm{CO}_{2}$ assimilation rate, leaf surface $\mathrm{CO}_{2}$ concentration $c_{\mathrm{s}}$ and leaf surface relative humidity $h_{\mathrm{s}}$ :

$g_{\mathrm{s}}=b+k \frac{A h_{\mathrm{s}}}{c_{\mathrm{s}}}$.

The values for the intercept $b$ and the dimensionless slope $k$ in this relationship are taken from Collatz et al. (1991) (Table 1). The leaf's aerodynamic conductance, $g_{\mathrm{b}}$, is described as a function of leaf size and wind speed, following Goudriaan (1977).

The mutual interaction between photosynthesis and stomatal conductance (stomatal conductance is affected by the $\mathrm{CO}_{2}$ assimilation rate $A$, and $\mathrm{CO}_{2}$ assimilation is affected 
by the leaf-internal $\mathrm{CO}_{2}$ concentration and thus by stomatal conductance) is determined iteratively by solving a squared function of the stomatal conductance $g_{\text {s }}$ applying bisection.

The transpiration flux $E$ is computed from the gradient between the water vapour concentrations in the stomata (assumed to be saturated, $\left.H_{\mathrm{i}}\right)$ and the outside air $\left(H_{\mathrm{a}}\right)$ using the stomatal and aerodynamic resistances for water vapour (denoted as $g_{\mathrm{s}}^{\prime}$ and $g_{\mathrm{b}}^{\prime}$, respectively) in series:

$E=\left(H_{\mathrm{i}}-H_{\mathrm{a}}\right)\left(g_{\mathrm{s}}^{\prime}+g_{\mathrm{b}}^{\prime}\right)$.

Driving variables for the model are PAR, $\mathrm{CO}_{2}$ concentration, humidity, temperature and wind speed. The model applies the simulated distributions of light (Sect. 2.2.1) and the observed vertical profiles of $\mathrm{CO}_{2}$, humidity, temperature and wind speed (Sect. 2.1.1). The observed vertical distribution of leaf area (Sect. 2.3) was used to integrate the leaf-scale photosynthesis and transpiration rates into the stand scale.

\subsection{Simulation set-up}

The photosynthesis-stomatal conductance model described above was applied to simulate leaf-level photosynthesis and transpiration in the canopy of the Norunda forest site. To do so, the canopy was distributed in 25 vertical layers of $1 \mathrm{~m}$ thickness, to which leaf density was prescribed according to the LAI profile for the site derived from the vertical leaf area distribution in the tree crowns (Morén et al., 2000) combined with an extensive stratified sampling of tree heights and tree crown lengths (Håkansson and Körling, 2002). Within these layers, the sunlit and shaded parts of the needles were separated as described above, and within each of these two fractions, a spherical leaf angle distribution was represented by $4 \times 4$ leaf normal azimuth and zenith angles. These 16 leaf angle classes were distributed over the hemisphere so that each of the 16 classes represents an equal fraction $(1 / 16)$ of the full distribution.

The light distribution model (Sect. 2.2.1 and Appendix A) was applied to simulate the leaf-level absorption of photosynthetically active radiation (PAR). For each layer, the concentrations of water vapour and $\mathrm{CO}_{2}$, as well as the temperature and wind speed, were obtained from linear interpolation of the within-canopy measurements (Sect. 2.1.1). These conditions varied between the layers, whereas the different leaf angle classes within one layer were considered to have the same temperature, wind speed and atmospheric concentrations of $\mathrm{CO}_{2}$ and $\mathrm{H}_{2} \mathrm{O}$. Because of the varying PAR between the classes, stomatal conductance, and thereby leaf-internal $\mathrm{CO}_{2}$ concentration, were able to vary between these as well.

Apart from these simulations in which the heterogeneity within the canopy was represented explicitly (hereafter referred to as simulation HET), a number of simulations were performed in which these conditions were averaged spatially, thereby removing part of the vertical heterogeneity. For these simulations, the conditions were prescribed to the (LAI-weighted) canopy average instead of the distribution, or in some cases to the above-canopy $(h=28.0 \mathrm{~m})$ or withincanopy $(h=8.5 \mathrm{~m})$ value. A complete overview of the simulations performed in this study is given in Table 2.

Moreover, the importance of vertical heterogeneity in forcing parameters was compared with the annual and diurnal variability in the forcing with the help of two sets of simulations in which this temporal variability was artificially removed for all parameters except one. These simulations were driven without annual heterogeneity (labelled as AHET in Table 2, applying an annually averaged vertical profile and diurnal cycle) for all parameters except one. Similarly, the simulations without diurnal heterogeneity (labelled as DHET, applying average daily conditions while maintaining the annual cycle and vertical profile) had the diurnal heterogeneity removed for all parameters except one. The simulated temporally varying vertical profiles of $\mathrm{CO}_{2}$ assimilation and transpiration were averaged per day and integrated over the canopy (AHET), averaged per half-hourly period of the day and integrated over the canopy (DHET), or averaged over both days and hours for each layer in the profile (HET), and the distributions (presented as percentiles) were computed.

\section{Results}

\subsection{Comparison with observations}

Photosynthesis and transpiration from the simulation in which the heterogeneity was accounted for (HET, Table 2) were compared with the photosynthesis derived from the observed $\mathrm{CO}_{2}$ flux and with the observed $\mathrm{H}_{2} \mathrm{O}$ flux, respectively, for the years 1999-2002.

The annual cycle of photosynthesis (Fig. 2a) was generally well captured by the model. The day-to-day variability was represented, with individual days with low photosynthesis resulting primarily from low incoming radiation on these days (not shown). A marked decrease in photosynthesis was observed for a 2 week period in 1999 starting from 28 July (days 209-223), likely as a result of a preceding period of drought, coinciding with low soil moisture values (not shown; Lagergren and Lindroth, 2002). This decrease was not captured by the model, because the impact of soil moisture conditions is not accounted for. The diurnal cycle for photosynthesis (Fig. 3a) was captured well by the model for all seasons, except for winter, when the model considerably overestimated photosynthesis. A similar 2 week drought occurred in 2001, starting at the end of June (Fig. 2a).

The annual cycle of transpiration (Fig. 2b) showed a reasonable agreement with the observed $\mathrm{H}_{2} \mathrm{O}$ flux (which consists of both evaporation and transpiration). In general, the observed flux was considerably higher than the simulated one in winter and spring (February-June), which can likely be attributed to a high contribution of evaporation to the $\mathrm{H}_{2} \mathrm{O}$ flux in spring, coinciding with the snow melt period. Transpiration estimates for 1999 from sapflow measurements 


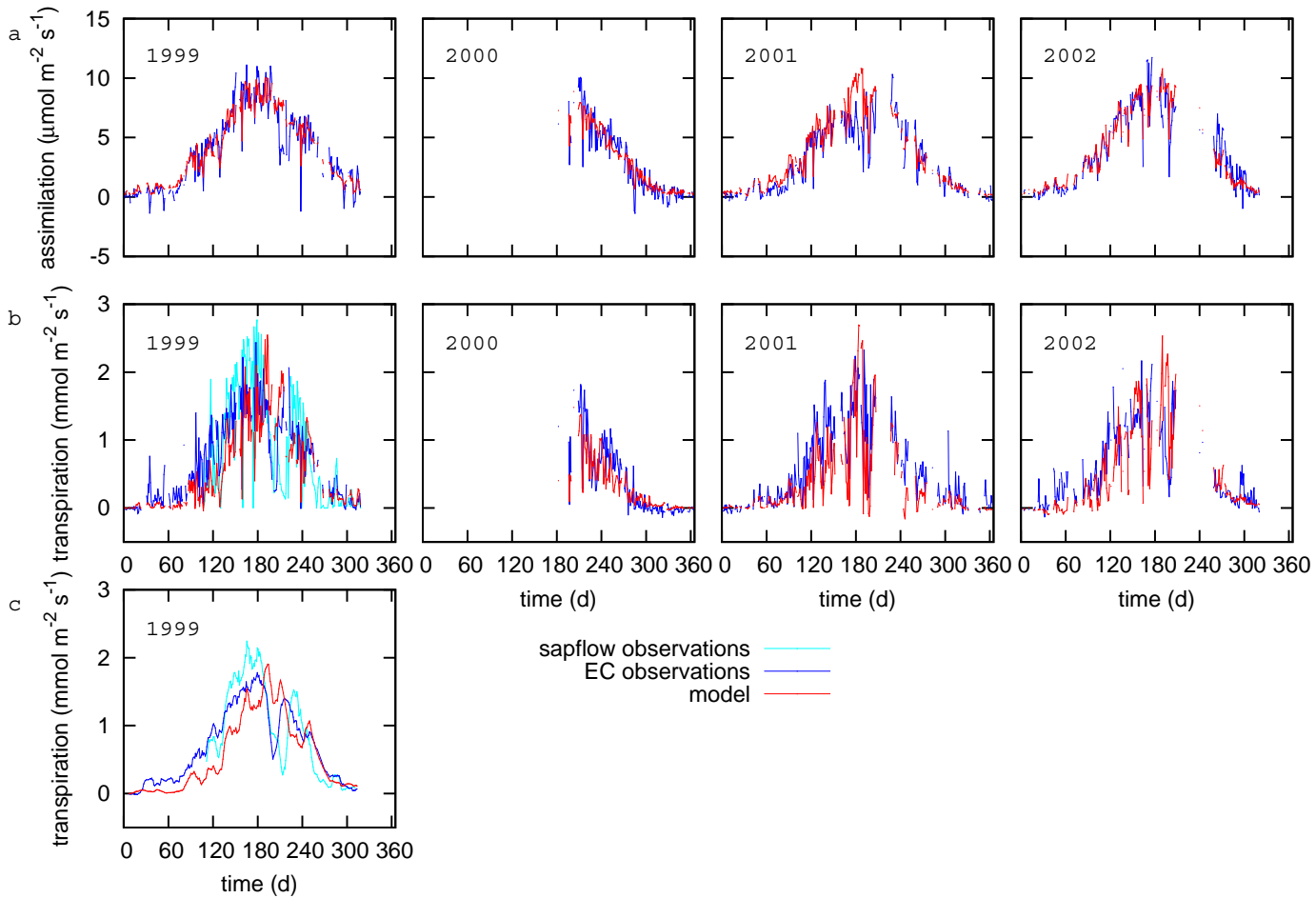

Figure 2. Annual cycle of simulated and observed daily mean (a) $\mathrm{CO}_{2}$ assimilation and (b) transpiration for the years 1999-2002. Note that the photosynthesis parameterisation was based on observations from 2001 (Thum et al., 2008). Days with fewer than 45 (out of 48 ) half-hourly observations were omitted. (c) 10 day running mean of simulated and observed daily mean transpiration for 1999.
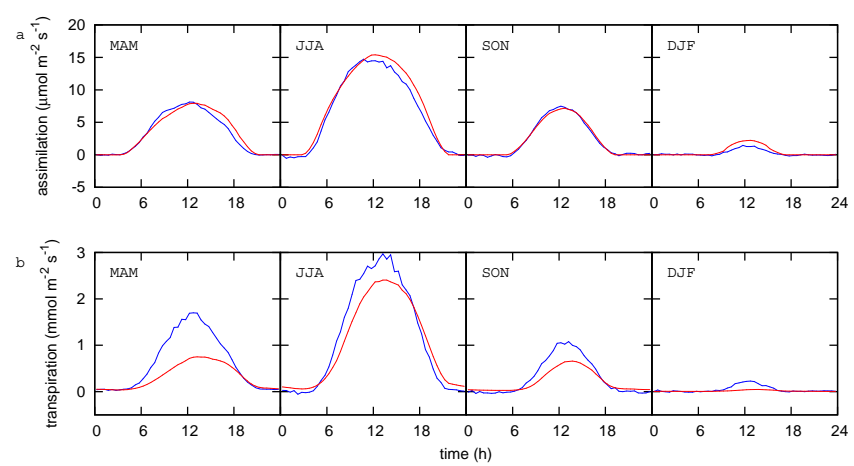

observations

Figure 3. Diurnal cycle of simulated and observed (a) $\mathrm{CO}_{2}$ assimilation and (b) transpiration, averaged for four seasons with data from 1999, 2000 and 2002.

(applying the tissue heat balance method, Lagergren and Lindroth, 2002) showed a later onset of transpiration (Fig. 2b and c), in better agreement with the simulated rates. The diurnal cycle of transpiration (Fig. 3b) showed this overestimation for winter and spring in the daytime, with a particular mismatch for the winter season, when simulated transpiration was negligible. For summer and autumn, however, the average diurnal cycle was captured well by the model, with a slight underestimation between 6 a.m. and noon.

Three 5 day periods were selected as case studies (Fig. 4), which are analysed below with respect to their within-canopy variations under environmental conditions (Fig. 4a-d). Case 1 (18-22 May 1999) was selected to represent large withincanopy gradients of humidity and temperature. Case 2 (2428 August 1999) represents large changes in sky conditions, and therefore large changes in the vertical distribution of light. Case 3 (8-12 September 1999) exhibits large gradients of atmospheric $\mathrm{CO}_{2}$ concentration within the canopy. For these cases, the dynamics of canopy-scale photosynthesis and transpiration (Fig. $4 \mathrm{~g}$ and $\mathrm{h}$ ) were captured well by the simulation model. Negative fluxes of $\mathrm{CO}_{2}$ assimilation in the observations (Fig. $4 \mathrm{~g}$ ) are due to the method used to separate the net $\mathrm{CO}_{2}$ flux into $\mathrm{CO}_{2}$ assimilation and ecosystem respiration, and represent the noise in the observation-based flux.

These cases were analysed in detail, after which the impact of heterogeneity was assessed at the annual level. Because of the small needle diameter, the leaf boundary layer is shallow, and the simulated exchange processes turned out to be insensitive to wind speed. Therefore, the analysis below will concentrate on humidity and temperature, PAR and $\mathrm{CO}_{2}$ concentration. 


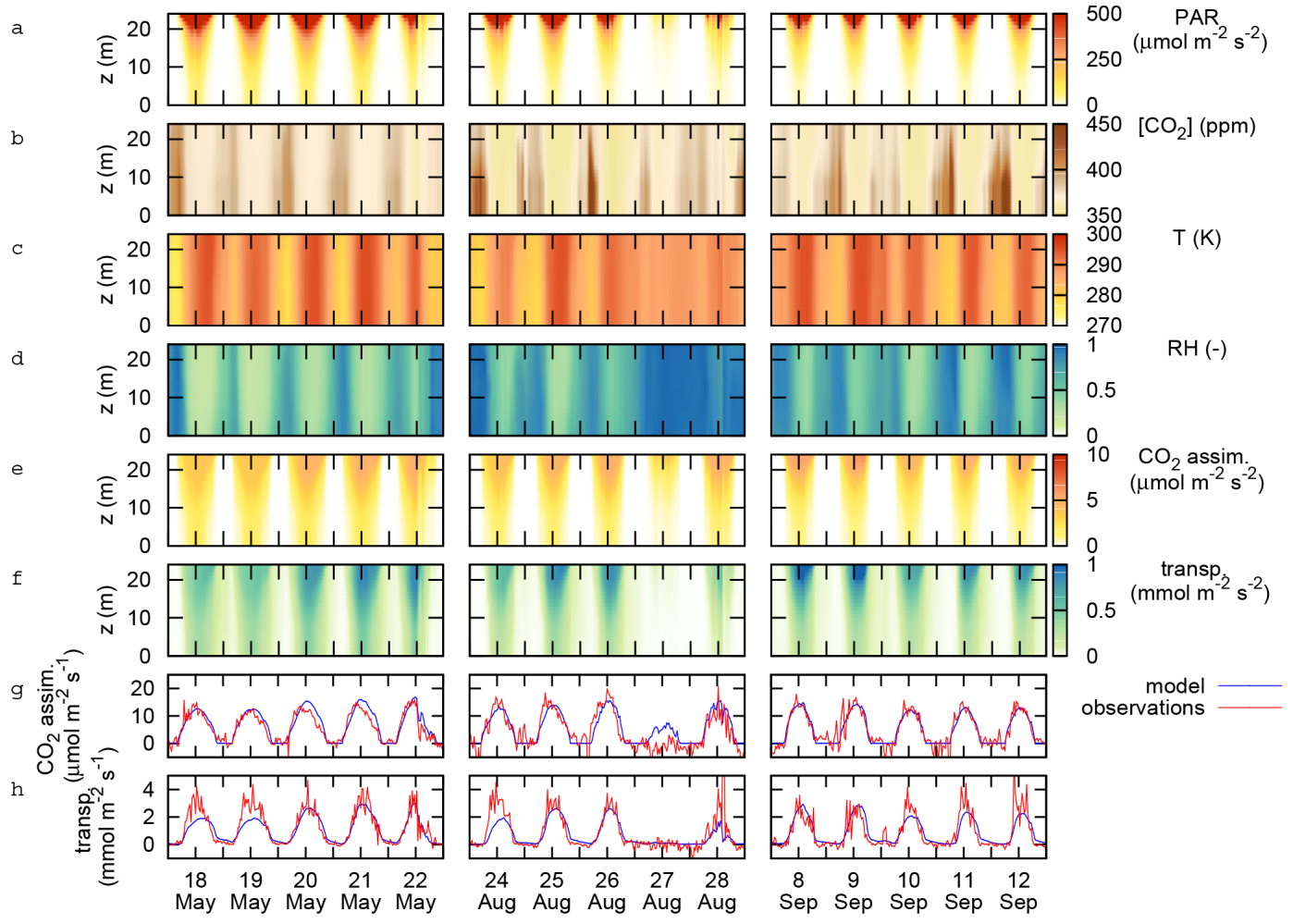

Figure 4. Overview of vertical gradients in the canopy for three periods: 18-22 May 1999 (case 1), 24-28 August 1999 (case 2) and 8-12 September 1999 (case 3). Shown are gradients of (a) leaf-level absorbed photosynthetically active radiation (PAR), averaged per canopy layer, (b) atmospheric $\mathrm{CO}_{2}$ concentration, (c) air temperature, (d) relative humidity, (e) simulated $\mathrm{CO}_{2}$ assimilation and (f) simulated transpiration, as well as the canopy-integrated (g) $\mathrm{CO}_{2}$ assimilation and (h) transpiration, compared with observed fluxes (the canopy-integrated fluxes in (g) and (h) are expressed per ground area). The gradient in PAR originates from detailed simulation of the light transfer in the canopy. Gradients in $\mathrm{CO}_{2}$, air temperature and relative humidity were obtained from linear interpolation of measurements at 5-6 levels in and directly above the canopy.

\subsection{Heterogeneity in humidity and temperature}

For the period of the first case study, 18-22 May 1999, the $\mathrm{CO}_{2}$ assimilation flux was captured well by the model (Fig. 4g), and the simulated transpiration flux was slightly underestimated for 18 and 19 May, whereas it was captured well for 20-22 May (Fig. 4h). During this 5 day period, there were marked differences between the conditions above the canopy and within the canopy (Fig. 5). In general, temperatures were up to $3 \mathrm{~K}$ higher above the canopy than within, and relative humidity was up to $15 \%$ lower. Differences were largest during nighttime, e.g. in the nights between 18 and 19 and between 19 and 20 May (Fig. 5a and b), but even in the early morning and late evening, while photosynthesis occurred, differences were apparent. The pattern of stomatal conductance (Fig. 5c) followed primarily that of photosynthesis (Fig. 4e), which is the main cause of the similarity in the vertical profiles of photosynthesis and transpiration (Fig. 4f).

Variations in relative humidity have two opposing effects: (1) a high relative humidity causes the stomatal conductance to be high (Eq. 7) and thereby stimulates transpiration and
$\mathrm{CO}_{2}$ assimilation, and (2) under high relative humidity, the humidity gradient between the substomatal cavity (which is assumed to be saturated) and the air surrounding the leaf is low, thereby hampering transpiration.

The simulation with homogeneous temperature (HOM_TEM) or humidity (HOM_HUM) resulted in very similar $\mathrm{CO}_{2}$ assimilation and transpiration compared with the simulation applying heterogeneous conditions (HET). Because the vertical variations in humidity and temperature were relatively small, and the response is reasonably linear, the deviations were not large (not shown).

However, when applying within-canopy $(8.5 \mathrm{~m}$, simulation HOM_HUM_IC) or above-canopy $(28 \mathrm{~m}$, simulation HOM_HUM_AC) humidity instead of the canopy-average value (Fig. 5d), transpiration can be over- or underestimated within the canopy (Fig. 5e-f), in particular in late evening, night and early morning, in line with the observed gradients for humidity (Fig. 5a). The lower humidity above the canopy, which caused the largest deviations, resulted in an overestimation of transpiration of up to $80 \%$ during the abovementioned time of the day (e.g., during the night from 19 


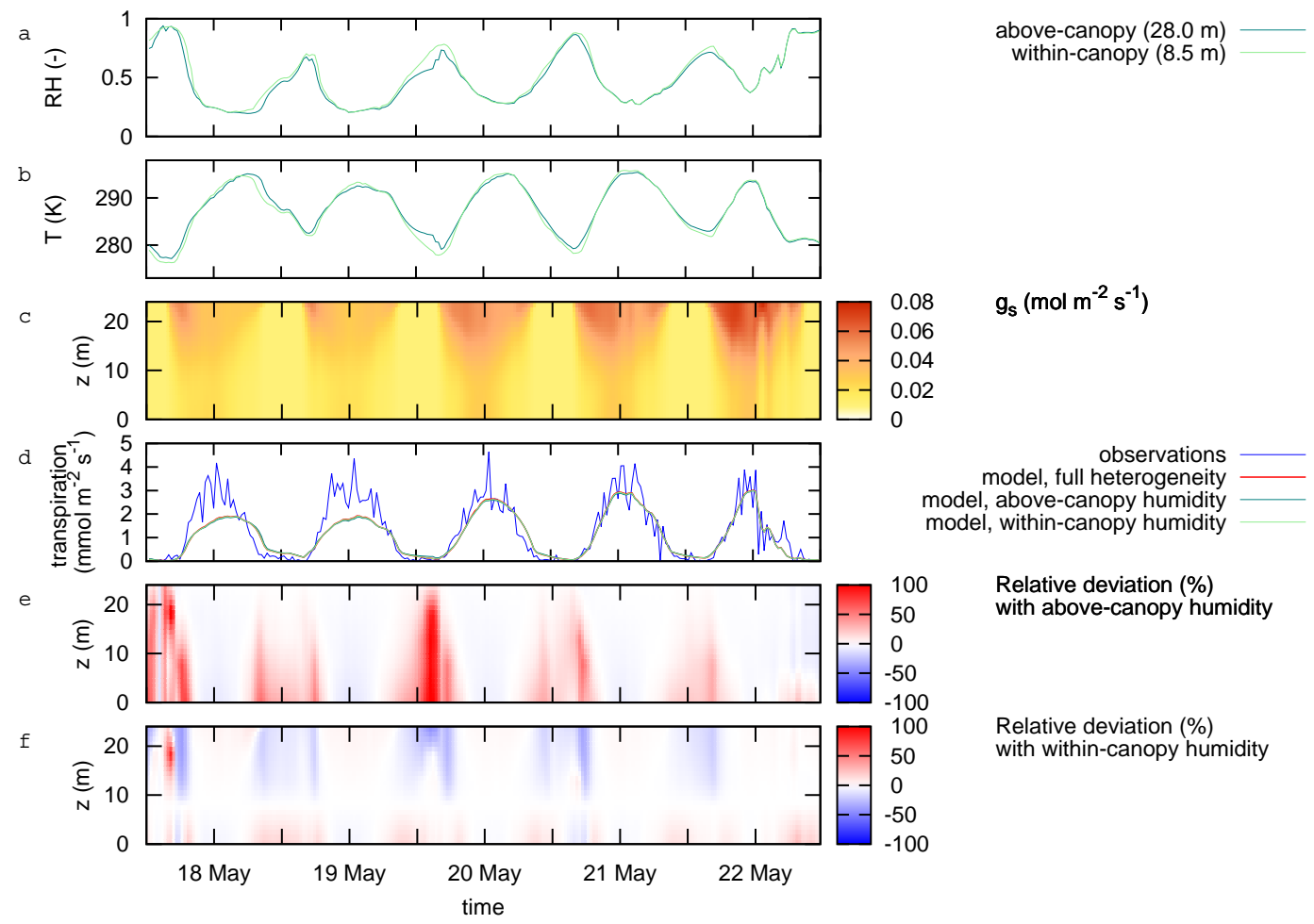

Figure 5. Effect of temperature and humidity conditions on transpiration for the case period 18 to 22 May 1999: (a) above-canopy (28.0 m) and within-canopy $(8.5 \mathrm{~m}$ ) relative humidity; (b) above-canopy and within-canopy temperature; (c) simulated profile of stomatal conductance, averaged per layer; (d) simulated transpiration, as well as observed $\mathrm{H}_{2} \mathrm{O}$ flux; (e) relative deviation in simulated transpiration when applying above-canopy humidity (simulation HOM_HUM_AC); (f) relative deviation in simulated transpiration when applying within-canopy humidity (simulation HOM_HUM_IC).

to 20 May). Applying the above-canopy conditions yielded reasonable results in the top of the canopy, but overestimated transpiration in the lower canopy (Fig. 5e). The use of within-canopy humidity caused reasonable results for the lower canopy (with no deviations for the actual height of the measurements, $8.5 \mathrm{~m}$ ), but with the top of the canopy depicting an underestimation of transpiration (Fig. 5f). From the two opposing effects mentioned above, the changes in humidity gradient were driving these deviations, whereas the stomatal response had only a mild counteracting effect.

The deviations can be considerable during the period with little or no daylight, but the difference disappeared during daytime. Hence, the daily total transpiration was only slightly affected, with 7 days exceeding an overestimation of $10 \%$ in the period April-September for the simulation with abovecanopy humidity, and 7 days exceeding an underestimation of $10 \%$ for the same period for the simulation with withincanopy humidity. On an annual basis, the total overestimation of the annual transpiration was $1.0 \%$ in the simulation with above-canopy humidity, and the underestimation was $1.6 \%$ in the simulation with within-canopy humidity (not shown). Effects of above-canopy or within-canopy temperature rather than the temperature average yielded even lower deviations in the simulated transpiration (not shown): an un- derestimation of $0.5 \%$ when using above-canopy temperature, and no difference when using within-canopy temperature. Because the changes in stomatal conductance were only minor, the simulated $\mathrm{CO}_{2}$ assimilation flux was affected less than the transpiration flux.

\subsection{Heterogeneity in light absorption}

Within-canopy heterogeneous light conditions were the most important contribution to the within-canopy heterogeneity of the simulated photosynthesis and transpiration rates. The case study period 24-28 August 1999 (Fig. 4) showed a marked difference in the vertical profiles of light absorption (Fig. 4a), photosynthesis (Fig. 4e) and transpiration (Fig. 4f) between clear days (e.g. 25 August) and overcast days (e.g. 27 August), resulting in canopy photosynthesis rates that differ greatly (Fig. 4g). These differences were largely caused by the absolute amounts of radiation.

The angular distribution of the light is often counteracting the impact of high levels of radiation. Figure 6a shows that the dominant part of the radiation was direct for $25 \mathrm{Au}-$ gust, whereas there was only diffuse radiation on 27 August. This distribution over direct and diffuse radiation affected the efficiency of the canopy to assimilate: With large amounts 
a

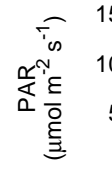

$\mathrm{b}$
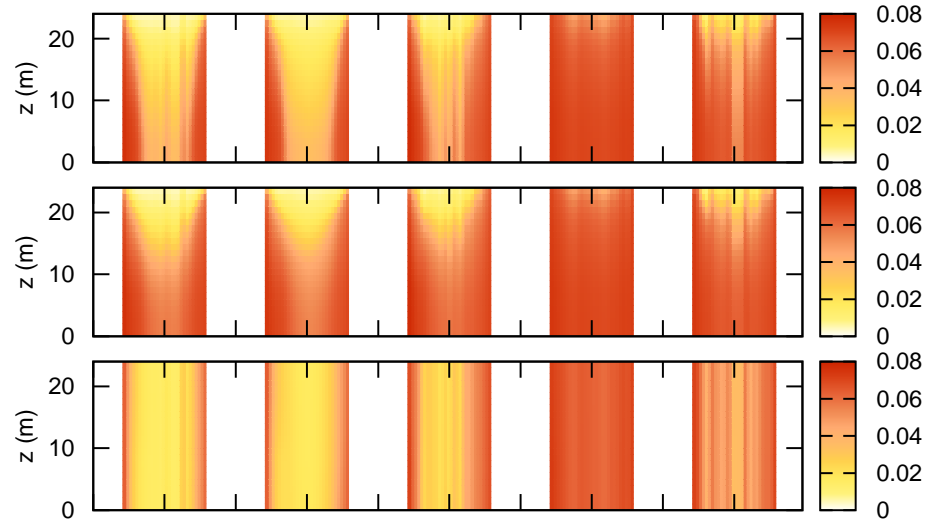

e

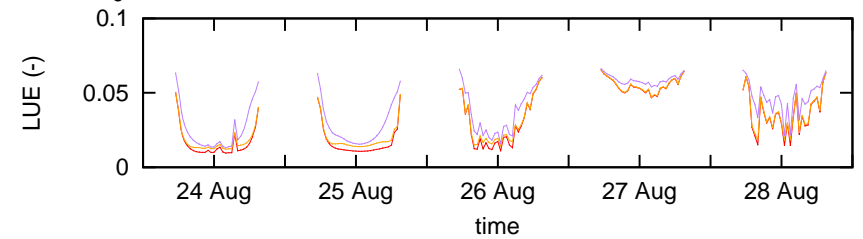

diffuse radiation direct radiation

LUE (-)

LUE (-)

LUE (-)

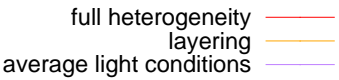

Figure 6. Light conditions and their distribution in the canopy for the case period 24 to 28 August 1999: (a) above-canopy photosynthetically active radiation (PAR, separated into direct and diffuse components); (b) light use efficiency (LUE, $\mathrm{CO}_{2}$ assimilation per unit of absorbed PAR) for the full heterogeneity case (simulation HET); (c) light use efficiency for a set-up that does not separate sunlit and shaded leaves (simulation HOM_PAR_LAYER); (d) light use efficiency for a set-up that separates neither sunlit and shaded leaves, nor layers (simulation HOM_PAR); (e) canopy-scale light use efficiency $\left(\mathrm{CO}_{2}\right.$ assimilation per unit of incoming PAR).

of direct radiation, part of the canopy is light-saturated and produces at its maximum rate. However, a large part of the canopy, most notably the shaded leaves, receive considerably lower amounts of radiation. In contrast, for overcast conditions, e.g. those prevailing on 27 August, the light is distributed more evenly in the canopy. This, combined with the generally lower level of radiation, makes that less leaves are under light-saturated conditions, and that the lower part of the canopy receives more light and is contributing more to the canopy photosynthesis.

The impact of sky conditions on the distribution of the light affected the light use efficiency (LUE, which is defined here as the $\mathrm{CO}_{2}$ assimilation flux per amount of absorbed PAR) of the canopy, both within the vertical profile (Fig. 6b) and for the canopy as a whole (Fig. 6e). Around noon on sunlit days, the absorption in the top of the canopy was high, and the LUE in the top of the canopy was low, resulting in lower canopy LUE values (Fig. 6e). In the early morning and late evening hours of clear-sky days, as well as on overcast days, the fraction of diffuse radiation was high and the absolute amount of incoming PAR was low, resulting in a more even distribution of the light in the canopy, and generally lower photosynthesis rates. In contrast to the low absolute amounts, the efficiency was higher, which resulted in improved canopy LUE.
The light extinction scheme applied here distinguishes leaf-level heterogeneity in light absorption caused by the distinction between sunlit and shaded leaves, the vertical layering of the canopy and the distribution of leaf angles. The contribution of these factors to the heterogeneity in $\mathrm{CO}_{2}$ assimilation, and thereby their impact on LUE, is illustrated in Fig. 6b-d. Simulation HOM_PAR_LAYER, which did not separate sunlit and shaded leaves or leaf angles, and which obtains its heterogeneity only from the layering in the canopy, had uniform conditions within the vertical layers, and represents a light extinction scheme that does not account for sunlit-shaded leaves, as is often applied in largescale models. It resulted in considerably higher LUE values (Fig. 6c), particularly in the lower part of the canopy, where the distinction between sunlit and shaded leaves results in a small proportion with high PAR levels and a large proportion with very low levels. An even more equal distribution of the light was obtained with simulation HOM_PAR (Fig. 6d), which had no layering in the canopy either. This represents the so-called big-leaf approach, as used in large-scale models that lack a vertical layering. It resulted in a homogeneous distribution of the light, and in the highest LUE values for the canopy (Fig. 6e).

The distinction between direct and diffuse radiation and the effect of the solar angle on light extinction and 


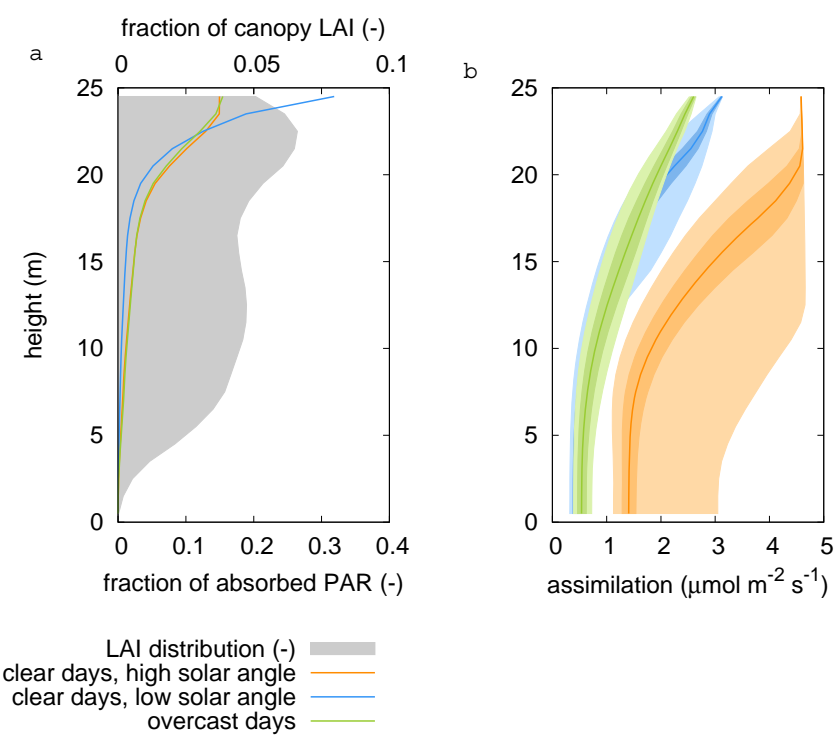

Figure 7. Vertical distribution of (a) light absorption and (b) $\mathrm{CO}_{2}$ assimilation in the canopy (expressed per leaf area), separated for clear time steps $\left(f_{\text {dif }}<0.5\right)$ with a solar angle $\beta>30^{\circ}(n=1418)$, clear time steps with a solar angle $\beta<30^{\circ}(n=1382)$, and cloudy time steps $\left(f_{\text {dif }} \geq 0.5, n=4888\right)$ for 1999 . The average distribution within a layer in (b) is represented by the median, 25-75\% percentile, and 5-95\% percentile.

distribution were important contributions to the withincanopy heterogeneity. Apart from the generally higher levels of radiation and hence $\mathrm{CO}_{2}$ assimilation obtained under high solar angles, the radiation penetrated deeper into the canopy, resulting in a more even distribution of the radiation (Fig. 7a) and higher levels of $\mathrm{CO}_{2}$ assimilation further down in the canopy (Fig. 7b) compared to cases with a low solar angle. Similarly, the high levels of diffuse radiation obtained under overcast conditions resulted in a more homogeneous distribution of the light because of the contributions from different azimuth and zenith angles, resulting in a more even vertical distribution of $\mathrm{CO}_{2}$ assimilation (Fig. 7).

This profound difference between clear and overcast conditions was obtained as well when separating the daily $\mathrm{CO}_{2}$ assimilation flux over clear days (defined here as days with more than $50 \%$ of the radiation reaching the canopy directly) and cloudy days (less than $50 \%$ of the radiation reaching the canopy directly): for clear days, lower efficiencies in $\mathrm{CO}_{2}$ assimilation with a given amount of light (Fig. 8) were obtained; the light use efficiency is depicted here as the slope in the figure. The model set-up depicting the full distribution of light in the canopy (simulation HET) was able to capture the efficiency for both the clear days and cloudy days, and showed a marked difference between the two. The set-up without heterogeneity in the canopy light distribution (simulation HOM_PAR) generally overestimated the efficiency because of the equal distribution of light. Moreover, the difference in light use efficiency between clear days and cloudy days was smaller. The model set-up used for HOM_PAR did not differentiate between direct and diffuse radiation, but the regression still depicted a difference because of the relative importance of high PAR days to the clear day set, which generally show a lower efficiency.

On the annual scale, GPP was captured well by the simulation applying full heterogeneity (simulation HET), with a slight overestimation of $3 \%$ of the annual GPP compared with the observations for the days for which data are available. The simulation without heterogeneity in the light distribution (HOM_PAR) overestimated GPP by $44 \%$ compared to this full heterogeneity set-up, whereas the simulation with a layering only (HOM_PAR_LAYER) overestimated GPP by $14 \%$.

\subsection{Heterogeneity in $\mathrm{CO}_{2}$ concentration}

Within the canopy, the ambient concentration of $\mathrm{CO}_{2}$ can vary considerably, both in time and in the vertical (Fig. 4b). Large gradients are formed under stable conditions during nighttime, when $\mathrm{CO}_{2}$ assimilation has stopped, but heterotrophic and autotrophic respiration continue, while vertical mixing is reduced in the canopy. These gradients disappear quickly after sunrise, when the boundary layer growth starts and initiates turbulent mixing. It is mainly during these early morning hours that effects of a $\mathrm{CO}_{2}$ gradient in the canopy on fluxes of $\mathrm{CO}_{2}$ assimilation and transpiration were to be expected.

These large gradients were seen in the third case period (Fig. 4b), and we will illustrate this impact by analysing the dynamics of this gradient on 12 September 1999 in more detail (Fig. 9). For this date, the $\mathrm{CO}_{2}$ gradient built up during nighttime, and a gradient of more than $50 \mathrm{ppm}$ was maintained up to two hours after sunrise (Fig. 9c). Ignoring this gradient in the simulation of $\mathrm{CO}_{2}$ assimilation by using a constant (canopy-average or above-canopy) $\mathrm{CO}_{2}$ concentration caused deviations of a few percents locally (Fig. 9d), but its impact on the actual profile (Fig. 9e), or on the canopy-integrated $\mathrm{CO}_{2}$ assimilation flux was negligible. From 8.30 a.m. onwards, the gradient disappeared rapidly, and had no further impact on $\mathrm{CO}_{2}$ assimilation during the day (Fig. 9c-e).

Despite the substantial gradient in $\mathrm{CO}_{2}$ concentration, its impact was small. This is because (1) photosynthesis largely takes place at the top of the canopy, where the deviations of the $\mathrm{CO}_{2}$ concentration from the above-canopy value is small (Fig. 9c and e), (2) during the early hours, the solar angle is low, so light does not penetrate deeply into the canopy, hence the lower leaves can barely profit from the higher $\mathrm{CO}_{2}$ concentrations, (3) leaves compensate for higher $\mathrm{CO}_{2}$ concentrations with a closure of their stomata (Ball et al., 1987, Eq. 7), which causes the gradient in stomatal concentrations to be much lower than that of atmospheric concentrations. The changes in the stomatal conductance in (3) have the potential to alter transpiration as well. In the cases where 


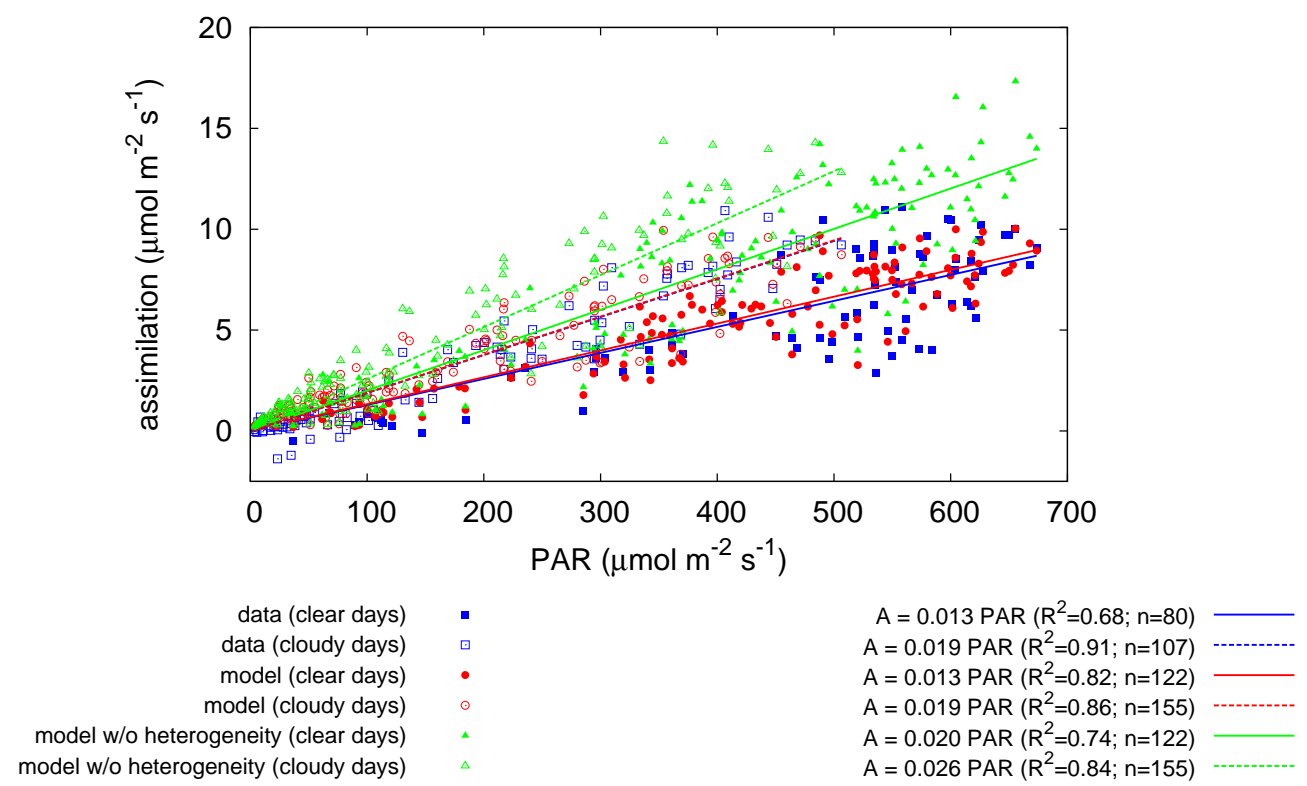

Figure 8. Daily integrated flux of $\mathrm{CO}_{2}$ assimilation as a function of the daily integrated photosynthetically active radiation (PAR) separated for clear days $\left(f_{\text {dif }}<0.5\right)$ and cloudy days $\left(f_{\text {dif }} \geq 0.5\right)$. Shown are results from the full heterogeneity simulation and the simulation without heterogeneity in light, as well as the observation-derived $\mathrm{CO}_{2}$ assimilation flux. Days with fewer than 45 (out of 48) half-hourly observations were omitted. Regression lines (obtained with least-squares linear regression through the origin) are shown for the three data sets as well (full lines corresponding to the clear days, dashed lines to the cloudy days).

photosynthesis is underestimated in the lower canopy, the simulations yield an underestimation of transpiration as well because of the lower $\mathrm{CO}_{2}$ concentration (not shown). However, similarly to the impact on photosynthesis, the change in transpiration had only a marginal impact, and occured where and when transpiration rates were small anyway.

The occurrence of $\mathrm{CO}_{2}$ gradients, predominantly during nighttime and morning hours, has therefore a negligible impact on canopy-integrated photosynthesis levels.

\subsection{Comparison with annual and diurnal heterogeneity}

The analysis above showed the vast dominance of light as the cause of within-canopy heterogeneity of $\mathrm{CO}_{2}$ assimilation and transpiration. A set of simulations that were forced by within-canopy heterogeneity of only one of the driving parameters (PAR, $\mathrm{CO}_{2}$, temperature and humidity, simulations HET_PAR, HET_CO2, HET_TEM and HET_HUM) illustrates this: Fig. 10a1 and b1 compare the observed variability in $\mathrm{CO}_{2}$ assimilation and transpiration fluxes within the canopy between the full heterogeneity simulation (HET) and the set of partial heterogeneity simulations. It clearly shows that the simulation in which light was the only heterogeneous variable (HET_PAR) had comparable variability for both $\mathrm{CO}_{2}$ assimilation and transpiration fluxes, whereas the other simulations had a much smaller variability.

In order to compare the importance of vertical heterogeneity with that obtained from annual and diurnal changes in the forcing, the variability was determined on the annual and diurnal scale for the two additional sets of simulations in which annual and diurnal heterogeneity in the forcing were removed, respectively. Figure $10 \mathrm{a} 2$ shows that the annual variability in the flux of $\mathrm{CO}_{2}$ assimilation is determined in equal amounts by variations in PAR and temperature. For the annual variability in transpiration, variability in humidity played a dominant role, with minor contributions from PAR and temperature as well (Fig. 10b2).

The diurnal variability of the $\mathrm{CO}_{2}$ assimilation flux was largely dominated by PAR (Fig. 10a3), which is the obvious driver of the daytime-to-nighttime difference in $\mathrm{CO}_{2}$ assimilation. Moreover, temperature contributed to the diurnal variability as well. For diurnal variations in transpiration, PAR and humidity changes played equal roles (Fig. 10b3).

Summarising, the within-canopy variability in fluxes of $\mathrm{CO}_{2}$ assimilation and transpiration was of a similar order of magnitude as the variability on annual or diurnal scales (Fig. 10), though typically slightly less than the latter. PARrelated variability within the canopy was of a similar magnitude as the PAR-related variability at the annual cycle.

\section{Discussion}

For the evaluation of the model, gross primary production (GPP) was derived from the $\mathrm{CO}_{2}$ flux determined with eddy covariance. To do so, respiration was substracted following Reichstein et al. (2005), however, the nighttime fluxes for Norunda did not always show a clear 
(a)

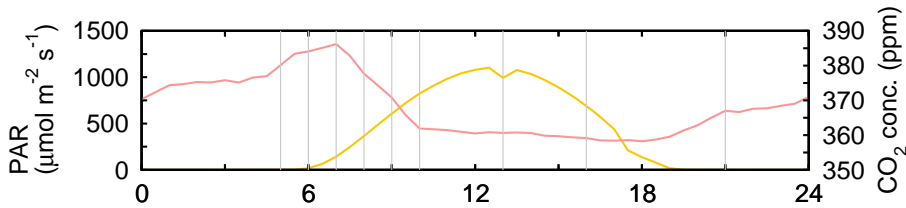

(b)

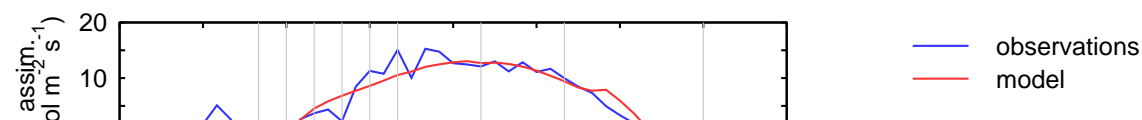

(c)
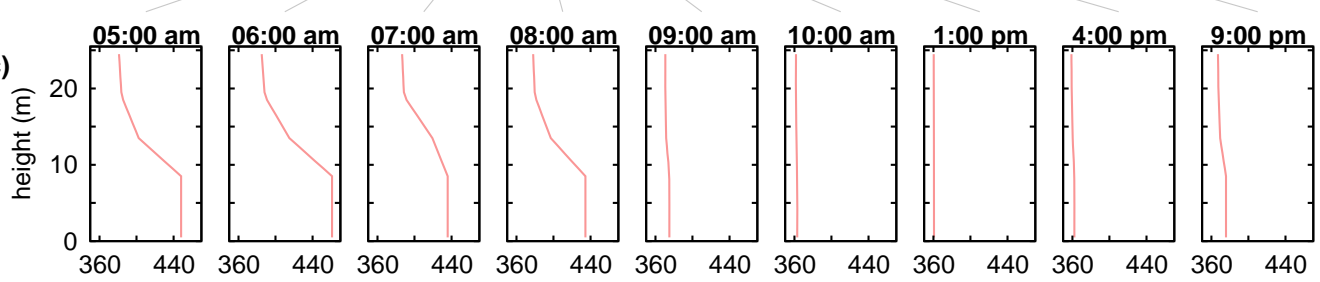

(d) $\mathrm{CO}_{2}$ conc. (ppm)
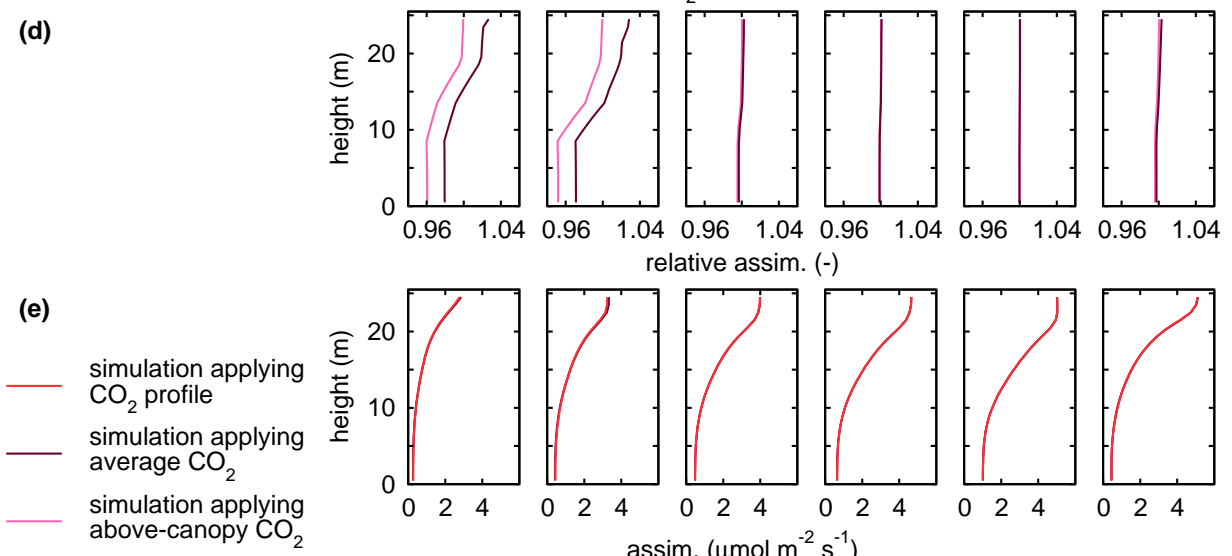

PAR

$\mathrm{CO}_{2}$ model relative assim. (-)

Figure 9. Changes in the within-canopy $\mathrm{CO}_{2}$ profile, and its impact on $\mathrm{CO}_{2}$ assimilation, illustrated for 12 September 1999: (a) observed changes in PAR and above-canopy $(28 \mathrm{~m}) \mathrm{CO}_{2}$ concentration; (b) simulated and observation-derived $\mathrm{CO}_{2}$ assimilation; (c) within-canopy $\mathrm{CO}_{2}$ profile for nine selected times; (d) relative deviations from simulated $\mathrm{CO}_{2}$ assimilation when applying average (simulation $\mathrm{HOM}$ _CO2) or above-canopy (simulation HOM_CO2_AC) $\mathrm{CO}_{2}$ concentrations instead of the distribution displayed in (c); (e) simulated $\mathrm{CO}_{2}$ assimilation for simulations applying the $\mathrm{CO}_{2}$ distribution as well as canopy-average or above-canopy $\mathrm{CO}_{2}$ concentration. For (d) and (e), only daytime panels were shown.

temperature dependence. Moreover, the comparison between the simulated canopy-scale transpiration and the $\mathrm{H}_{2} \mathrm{O}$ flux determined with eddy covariance showed large deviations in winter and spring, most likely caused by the contribution of evaporation to the flux, as supported by the improved comparison between model and observations obtained with sapflow measurements (Lagergren and Lindroth, 2002). Unfortunately, sapflow measurements were available only for a nearby (distance approximately $500 \mathrm{~m}$ ) site, and not for all years used in the model evaluation.

The model simulated $\mathrm{CO}_{2}$ assimilation and transpiration fluxes as a function of atmospheric conditions, but did not account for soil conditions. Soil moisture limitations may affect the stomatal conductance, and thereby the fluxes of $\mathrm{CO}_{2}$ assimilation and transpiration. Such water limitation occasionally occurred in the forest site studied here, mainly during summertime and for periods of up to 15 days (Jansson et al., 1999; Grelle et al., 1999; Lagergren and Lindroth, 2002; Thum et al., 2007), but the non-water limited results are representative of this site for most of the year. For other sites, it may be considerably more important to capture this response.

Despite these drawbacks, simulated and observed $\mathrm{CO}_{2}$ assimilation fluxes showed a good agreement, and simulated transpiration showed a reasonable agreement with the observed evapotranspiration.

The heterogeneity set-up applied in this study captured the main drivers of photosynthesis and transpiration in the 
1 vertical variability
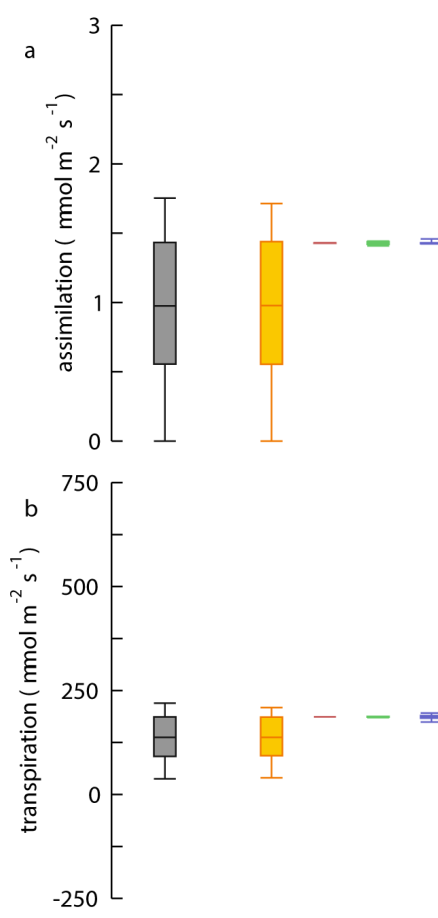

2 annual variability
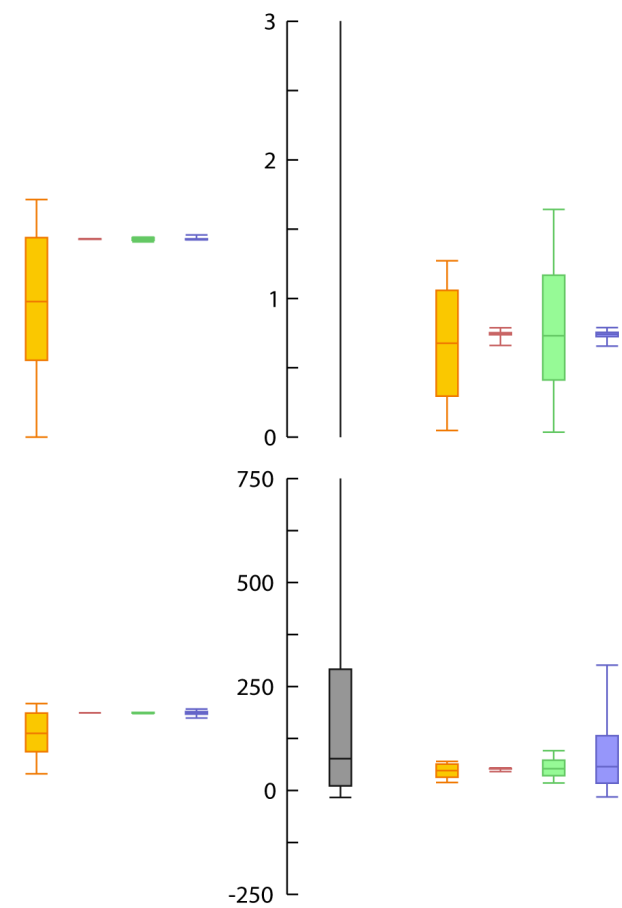

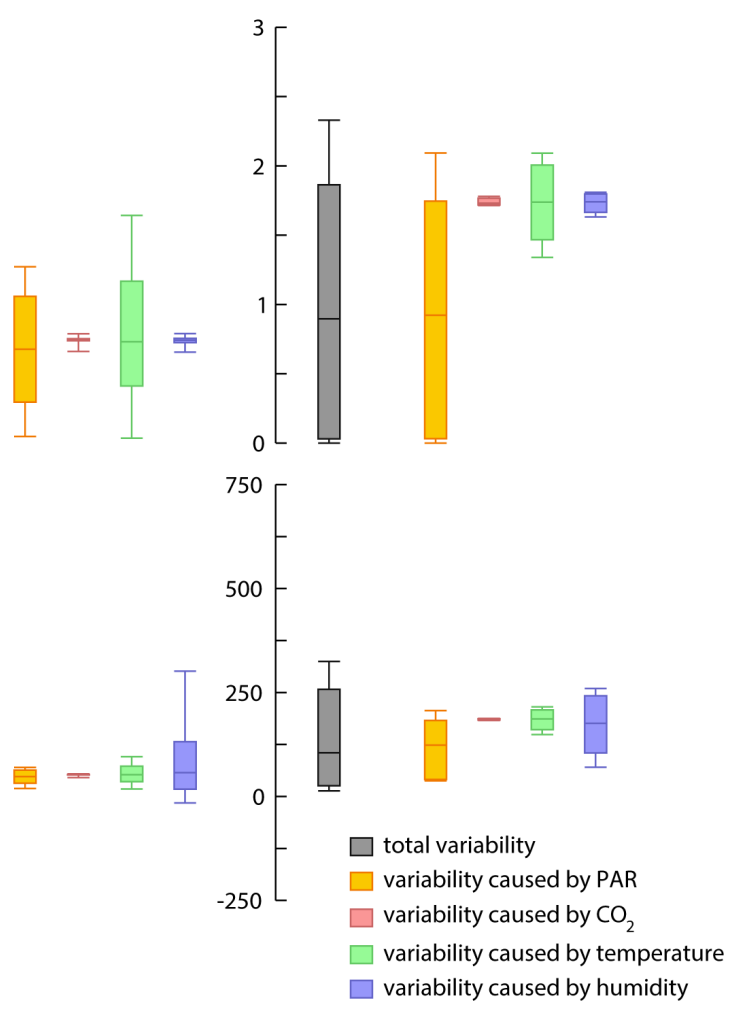

3 diurnal variability

Figure 10. Explanation of variability of simulated (a) $\mathrm{CO}_{2}$ assimilation and (b) transpiration for (1) vertical variability $(n=25)$, (2) annual variability $(n=277)$ and (3) diurnal variability $(n=48)$. Shown are the distributions (box indicates the median and the $25-75 \%$ percentile, whiskers indicate full distribution) obtained from the full simulation, and from simulations that exhibit variability only for one parameter (see text for details).

canopy, and showed that the vertical distribution of photosynthetically active radiation is the dominating source of vertical heterogeneity. The importance of sky conditions for the flux of $\mathrm{CO}_{2}$ assimilation has been studied in other coniferous forests. Considerably higher photosynthetic light use efficiency, and thereby a stronger net carbon sink, was observed for cloudy days as compared with clear days for a Picea abies stand in the Czech Republic (Urban et al., 2007), for two Picea sitchensis stands in the UK (Dengel and Grace, 2010), and for a Pinus sylvestris stand in Finland (Law et al., 2002), in agreement with the results presented in this study.

Stomatal conductance was observed to be larger for cloudy conditions than for clear conditions (Dengel and Grace, 2010), for which the enhancement of light absorption and thereby photosynthesis is only one possible explanation: In general, cloudy conditions coincide with a relatively low vapour pressure deficit, which enhances stomatal conductance as well. Our results suggest that this is of little importance for the diurnal dynamics of photosynthesis, but it may be more important for the seasonal dynamics (as addressed by Dengel and Grace, 2010). Moreover, the higher contribution of blue light to the radiation under diffuse conditions has been suggested as an explanation for higher conductance
(Dengel and Grace, 2010), but this was not confirmed for the Picea abies stand in Czech republic (Urban et al., 2012). These effects of spectral differences cannot be studied with our model in its current form, but may be interesting for future model development.

Variability within the $\mathrm{CO}_{2}$ profile had little effect on the simulated canopy $\mathrm{CO}_{2}$ assimilation rates in this study, mainly due to the counteracting effects of changes in ambient $\mathrm{CO}_{2}$ and changes in stomatal conductance (and thereby leaf-internal $\mathrm{CO}_{2}$ ). Brooks et al. (1997) estimated an increase of 5-6\% in understorey $\mathrm{CO}_{2}$ assimilation due to the elevated levels of $\mathrm{CO}_{2}$ resulting from respiration for two boreal forest sites in Canada. However, the understorey is not likely to contribute substantially to the canopy GPP. Rough estimates of ground vegetation net primary production for this site (unpublished results) indicate a contribution of less than $10 \%$ to the total, which is in the range obtained for other Swedish forest sites (Berggren et al., 2002). We expect the contribution to GPP to be of similar magnitude.

Similarly, the temperature gradients observed for this site had little impact on the simulated photosynthesis and transpiration. It needs to be noted that the heterogeneity in temperature used here was derived from air 
temperature measurements in a number of layers, and is thus not entirely representative of leaf temperatures. Importantly, leaf temperatures are affected by fluxes of radiation, and sunlit and shaded leaves may thus exhibit different temperatures. Observations of individual leaf temperatures, and their distribution in the canopy, are rare, and in order to investigate the importance of temperatures further, a leaf energy balance model may be used to compute temperatures.

Apart from the variations in the environmental driving variables, variations can occur in model parameters as well. The vertical gradient in light availability causes plants to distribute the leaf nitrogen content, and thereby the photosynthetic capacity, with a similar vertical gradient (Hirose and Werger, 1987; Givnish, 1988); in models this effect is often translated into an assumed optimum vertical distribution of nitrogen and photosynthetic capacity (De Pury and Farquhar, 1997). We have performed sensitivity tests applying an exponentially decreasing $V_{c \text {, max }}$ as suggested by De Pury and Farquhar (1997), resulting in an enhanced vertical gradient in $\mathrm{CO}_{2}$ assimilation under all sky conditions, and a further decrease in the light use efficiency. On the canopy scale, the light use was affected equally under clear or cloudy days, causing a reduction of $16 \%$ in LUE.

Similarly, temporal variations of photosynthetic capacities occur during the growing season, which was found for the Norunda forest site as well (Thum et al., 2008). However, Op de Beeck et al. (2010) found these seasonal variations to be relatively unimportant for the simulation of net ecosystem exchange in a Pinus sylvestris forest in Belgium. Apart from the vertical heterogeneity, there is a difference in these photosynthetic parameters as well between tree species. Pinus sylvestris has been observed to have generally higher rates of $\mathrm{CO}_{2}$ assimilation than Picea abies, both for the Rubiscolimited (Eq. 4) and for the electron transport-limited (Eq. 5) regimes (e.g. Wullschleger, 1993; Thum et al., 2008). In the current model, this separation, which requires the interaction between two (or more) tree species to compute the light transfer, cannot be accounted for. Moreover, such a separation would enhance uncertainties related to the parameterisation.

\section{Conclusions}

The simulations of fluxes of $\mathrm{CO}_{2}$ assimilation and transpiration for a boreal coniferous forest in central Sweden revealed that the gradient of PAR is the main driver of vertical heterogeneity within the canopy. Because of the concave shape of the response of photosynthesis to light, averaging of PAR in the canopy resulted in an overestimation of the photosynthesis rate. The other driving variables tested here (temperature, $\mathrm{CO}_{2}$ concentration, humidity and wind speed) had little impact on the canopy-integrated rates of photosynthesis and transpiration, and these can be well represented by a canopyaverage value.

In models applied on regional or global scales, vertical heterogeneity in the driving variables is largely ignored. Whereas a canopy-average value is sufficient to represent temperature, $\mathrm{CO}_{2}$ concentration and humidity, the distribution of PAR needs to be represented in more detail than a big-leaf approach, a result in accordance with earlier studies (Roderick et al., 2001; Alton et al., 2007; Knohl and Baldocchi, 2008; Mercado et al., 2009). A more detailed representation in large-scale models will enable a more realistic treatment of the effects of sky conditions on photosynthesis.

Given the size of the vertical variability of the fluxes of $\mathrm{CO}_{2}$ assimilation and transpiration within the canopy, which was shown to be of similar magnitude as the variability occurring on diurnal or annual timescales, the impact of forest structure on microclimatic conditions should receive more attention in large-scale models. For studies addressing changes over decades or more, not only physiological changes should be considered, but the changes in canopy structure and hence in micrometeorological conditions may affect exchange processes as well. 


\section{Appendix A: Description of light extinction scheme}

Light extinction was simulated with a numerical scheme that builds on existing theory, representing the heterogeneity in the canopy due to sunlit and shaded fractions (which was introduced by Duncan et al., 1967), vertical layering (used for representing the vertical heterogeneity by e.g. Monteith, 1965; Duncan et al., 1967; Cowan, 1968) and leaf angle distribution (addressed with numerical approximations by Goudriaan, 1977, 1988). However, in contrast to existing schemes, we refrain from averaging intermediate results (e.g. the distribution of insolation levels obtained from varying leaf angles) over the canopy, so that the distribution obtained represents the full distribution of light at the leaf level.

\section{A1 Leaf angle distribution}

Leaf orientation is represented by two dimensions: an azimuth angle $\phi_{l}\left(0 \leq \phi_{l}<360^{\circ}\right)$ and a zenith angle $\theta_{l}(0 \leq$ $\left.\theta_{l}<90^{\circ}\right)$ of the leaf normal. The distribution of leaf orientation in these two dimensions is represented in a discrete manner as a lattice with $n_{l \phi} \times n_{l \theta}$ combinations of azimuth and zenith angles. The spacing in $\phi$ and $\theta$ is done so that each combination $\left(\phi_{l}, \theta_{l}\right)$ has an equal likelihood, and represents $1 /\left(n_{l \phi} n_{l \theta}\right)$ of the complete leaf area. For the simulations in this study, we applied a spherical (or isotropic) leaf angle distribution, which is obtained with a uniform distribution (equal spacing) of the azimuth angles $\phi_{l}$ over the entire $360^{\circ}$, and a spacing at equal distances between the cosines of the angles for the zenith angles $\theta_{l}$, so that the increasing density towards the horizon compensates for the increasing area of the sphere.

\section{A2 Distribution of sunlight and skylight}

In the model, sunlight is described as a point source with a given azimuth and zenith angle $\phi_{\text {sun }}$ and $\theta_{\text {sun }}$, respectively, together with a photosynthetic quantum flux density $I_{\text {sun }}$ (in mol m${ }^{-2} \mathrm{~s}^{-1}$ ). Similar to the leaf angles, skylight is described with a distribution of azimuth and zenith angles over the hemisphere. In contrast to the leaf angle distribution, however, azimuth and zenith angles are spaced equally, resulting in $n_{i \phi} \times n_{i \theta}$ combinations of $\left(\phi_{s}, \theta_{s}\right)$, and the intensity for each combination is given by $I_{S}\left(\phi_{s}, \theta_{S}\right)$. The distribution of the light over sunlight (direct radiation) and skylight (diffuse radiation), as well as the distribution of skylight over all angles $\left(\phi_{s}, \theta_{s}\right)$, is determined by sky conditions.

To accommodate upward scattering of light within the canopy, a second hemisphere was introduced, which has the same number and distribution of azimuth and zenith angle classes.

\section{A3 Light absorption}

The canopy is represented by $n_{h}$ layers, and light absorption, reflection and transmission in the canopy are calculated by combining the direct radiation and the distribution of skylight radiation over the sky angles (Sect. A2) for each of the leaf orientations (Sect. A1) in each layer, thus resulting in a probability density function of leaf-level absorbed radiation. Below, we will describe the processes at the leaf level first, followed by a description of the aggregation of these processes to canopy scale.

The leaf angle distribution is assumed to be spherical (or isotropic), meaning that the leaf area in layer $h, L_{h}$, is distributed equally over all leaf angle orientations $\left(\phi_{l}, \theta_{l}\right)$, which is commonly used to describe a generic canopy in large-scale models (Cowan, 1968; Leuning et al., 1995) The leaf area was divided into a sunlit and a shaded fraction (computation of these fractions will be explained further down). This leaf area intercepts a fraction of the radiation that comes from a given direction $\left(\phi_{s}, \theta_{s}\right)$ proportional to its area, and it depends on the angle between the leaf normal and the direction of the radiation:

$f_{\text {int }, s, l, h}=\frac{\sin \gamma_{s, l}}{\cos \theta_{s}} \frac{L_{h}}{n_{l \phi} n_{l \theta}}$.

In this equation, the angle between beam and leaf, $\gamma_{s, l}$, can be computed from the inner product of the vectors of the beam and the leaf normal, which can be expressed based on their azimuth angles $\phi$ and zenith angles $\theta$ (see e.g. Ross, 1981):

$$
\begin{aligned}
& \gamma_{s, l}=\arcsin \left(\cos \phi_{s} \sin \theta_{s} \cos \phi_{l} \sin \theta_{l}\right. \\
& \left.+\sin \phi_{s} \sin \theta_{s} \sin \phi_{l} \sin \theta_{l}+\cos \theta_{s} \cos \theta_{l}\right)
\end{aligned}
$$

This intercepted fraction of the radiation, $f_{\text {int }, s, l, h}$ (Eq. A1) is absorbed, reflected or transmitted by the leaf, which is distributed according to constant fractions. To obtain the total amount of intercepted diffuse radiation by the leaf $I_{\mathrm{dif}, l, h}$ (which represents intercepted radiation by the leaf area with orientation $l$ in layer $h$ ), these fractions, multiplied by the light intensities $I_{\mathrm{dif}}$, need to be integrated over all skylight angles:

$I_{\mathrm{dif}, l, h}=\sum_{s=1}^{n_{s}}\left(f_{\mathrm{int}, s, l, h} I_{\mathrm{dif}, s} \sin \gamma_{s, l}\right)$.

This integration is performed both for the upper hemisphere and for the lower one to accommodate fluxes from below due to scattering.

Similarly, the fraction of intercepted beam radiation can be computed from Eq. (A1) by replacing the skylight angles with sunlight angles, which results in the beam radiation intercepted by a leaf with orientation $l$ in layer $h$ of

$I_{\text {sun }, l, h}=f_{\text {int,sun, }, l} I_{\text {sun }} \sin \gamma_{\text {sun }, l}$.

The total amount of intercepted radiation by the leaf area with orientation $l$ in layer $h$, which can be written as $I_{\text {sun }, l, h}+f_{\mathrm{sun}, h} I_{\mathrm{dif}, l, h}$ for sunlit leaves, and $\left(1-f_{\mathrm{sun}, h}\right) I_{\mathrm{dif}, l, h}$ for shaded leaves, is distributed over the sunlit and shaded 
leaf areas, respectively, to obtain the radiation intensity at the leaf level:

$$
\begin{aligned}
& I_{\text {int,sunlit }, l, h}=\frac{I_{\text {sun }, l, h}+f_{\text {sun }, h} I_{\text {dif }, l, h}}{f_{\text {sun }, h} n_{l \phi} n_{l \theta} L_{h}} \\
& I_{\text {int,shaded }, l, h}=\frac{I_{\text {dif }, l, h}}{n_{l \phi} n_{l \theta} L_{h}}
\end{aligned}
$$

The fractions of sunlit and shaded leaves are computed from the same theory: the total interception of radiation in layer $h$ is calculated by integrating Eq. (A1) over all leaf angles:

$$
f_{\text {int }, h}=\sum_{l=1}^{n_{l \phi} n_{l}} f_{\text {int, } 1}\left(\phi_{l}, \theta_{l}\right) .
$$

The fraction of sunlit leaves for each layer $h$ is computed from the shading in the layers above, assuming the leaves to be distributed randomly in space (no spatial aggregation), similar to Monteith (1965):

$f_{\text {sun }, h}=\left(1-f_{\text {int }}\right)^{h-1}$.

This results in an exponential profile of the sunlit fraction in the canopy.

The absorbed photon flux densities at the leaf level, obtained from Eqs. A5 and A6, are used to compute $\mathrm{CO}_{2}$ assimilation (see Sect. 2.2.2). The unintercepted radiation passes the layer without adjustments to the angular distribution. The radiation transmitted and reflected is distributed again over the two hemispheres of diffuse radiation. The leaf surface is assumed to be a Lambertian scatterer: the leaf reflects the largest flux in the direction of the leaf normal, and transmits the largest flux in the opposite direction. When the diffuse light reaches the leaf surface from below, transmittance points in the direction of the leaf normal, and reflectance in the opposite direction.
These leaf-level processes can be aggregated to the canopy level. For all leaf orientations $j$ in all layers $h$, absorbance, reflectance and transmittance from the layer as a whole can be determined as described above. Within a layer, the scattering in all directions of the upward and downward pointing hemisphere is integrated over all leaf orientations, and these amounts are added to the fluxes of diffuse radiation that pass through the layer without interference with the leaves.

The distribution of this scattered light over the canopy is solved iteratively by computing the total absorption of both downward and upward pointing fluxes for all layers, first from top to bottom, then from bottom to top. This is repeated until the remaining scattered light within the canopy is lower than a pre-defined minimum residual $(0.001 \%)$. This way of distributing the light in the model canopy is relatively efficient; it requires a few iterations to reach this residual.

The two-directional treatment of scattering is similar to that used in the models by Norman et al. (1971) and Norman (1975). The model described here contrasts with that approach, however, in the explicit description of angular scattering, and the numerical solution that is used to obtain that. 
Acknowledgements. This research was supported by the Swedish Research Council (Vetenskapsrådet), grant 2009-4290, and by LUCCI (Lund University centre for studies of Carbon cycle and Climate Interactions).

Edited by: T. Keenan

\section{References}

Alton, P. B., North, P. R., and Los, S. O.: The impact of diffuse sunlight on canopy light-use efficiency, gross photosynthetic product and net ecosystem exchange in three forest biomes, Glob. Change Biol., 13, 776-787, 2007.

Arx, G. V., Dobbertin, M., and Rebetez, M.: Spatio-temporal effects of forest canopy on understory microclimate in a long-term experiment in Switzerland, Agr. Forest Meteorol., 166-167, 144$155,2012$.

Aubinet, M., Berbigier, P., Bernhofer, C., Cescatti, A., Feigenwinter, C., Granier, A., Grünwald, T., Havrankova, K., Heinesch, B., Longdoz, B., Marcolla, B., Montagnani, L., and Sedlak, P.: Comparing $\mathrm{CO}_{2}$ storage and advection conditions at night at different Carboeuroflux sites, Bound.-Lay. Meteorol., 116, 63-93, 2005.

Baldocchi, D. D. and Wilson, K. B.: Modeling $\mathrm{CO}_{2}$ and water vapor exchange of a temperate broadleaved forest across hourly to decadal time scales, Ecol. Model., 142, 155-184, 2001.

Ball, J., Woodrow, I. E., and Berry, J. A.: A model predicting stomatal conductance and its contribution to the control of photosynthesis under different environmental conditions, in: Progress in Photosynthesis Research IV, edited by: Biggens, J., 221-224, Martinus Nijhoff Publishers, 1987.

Berggren, D., Johansson, M., J., Langvall, O., Majdi, H., and Melkerud, P. A.: Description of common field sites and database, in: Land use strategies for reducing net greenhouse gas emissions, edited by: Olsson, M., 9-27, Swedish University of Agricultural Sciences, Uppsala, 2002.

Brooks, J. R., Flanagan, L. B., Varney, G. T., and Ehleringer, J. R.: Vertical gradients in photosynthetic gas exchange characteristics and refixation of respired $\mathrm{CO}_{2}$ within boreal forest canopies, Tree Physiol., 17, 1-12, 1997.

Buchmann, N., Kao, W.-Y., and Ehleringer, J. R.: Carbon dioxide concentrations within forest canopies - variation with time, stand structure, and vegetation type, Glob. Change Biol., 2, 421-432, 1996.

Čermák, J., Deml, M., and Penka, M.: A new method of sap flow rate determination in trees, Biol. Plantarum, 15, 171-178, 1973.

Collatz, G., Ball, J., Grivet, C., and Berry, J. A.: Physiological and environmental regulation of stomatal conductance, photosynthesis and transpiration: a model that includes a laminar boundary layer, Agr. Forest Meteorol., 54, 107-136, 1991.

Cowan, I. R.: The interception and absorption of radiation in plant stands, J. Appl. Ecol., 5, 367-379, 1968.

De Pury, D. G. G., and Farquhar, G. D.: Simple scaling of photosynthesis from leaves to canopies without the errors of big-leaf models, Plant Cell Environ., 20, 537-557, 1997.

Dengel, S. and Grace, J.: Carbon dioxide exchange and canopy conductance of two coniferous forests under various sky conditions., Oecologia, 164, 797-808, 2010.
Duncan, W., Loomis, R., Williams, W., and Hanau, R.: A model for simulating photosynthesis in plant communities, Hilgardia, 38, 181-205, 1967.

Ellsworth, D. S. and Reich, P. B.: Canopy structure and vertical patterns of photosynthesis and related leaf traits in a deciduous forest, Oecologia, 96, 169-178, 1993.

Falge, E., Ryel, R. J., Alsheimer, M., and Tenhunen, J. D.: Effects of stand structure and physiology on forest gas exchange: a simulation study for Norway spruce, Trees, 11, 436-448, 1997.

Farquhar, G. D., Caemmerer, S. V., and Berry, J. A.: A biochemical model of photosynthetic $\mathrm{CO}_{2}$ assimilation in leaves of $\mathrm{C}_{3}$ species, Planta, 149, 78-90, 1980.

Feigenwinter, C., Mölder, M., Lindroth, A., and Aubinet, M.: Spatiotemporal evolution of $\mathrm{CO}_{2}$ concentration, temperature, and wind field during stable nights at the Norunda forest site, Agr. Forest Meteorol., 150, 692-701, 2010.

Givnish, T. J.: Adaptation to sun and shade: a whole-plant perspective, Aust. J. Plant Physiol., 15, 63-92, 1988.

Goudriaan, J.: Crop micrometeorology: a simulation study, Pudoc, Wageningen, 1977.

Goudriaan, J.: The bare bones of leaf-angle distribution in radiation models for canopy photosynthesis and energy exchange, Agr. Forest Meteorol., 43, 155-169, 1988.

Goulden, M. L., Munger, J. W., Fan, S.-M., Daube, B. C., and Wofsy, S. C.: Measurements of carbon sequestration by longterm eddy covariance: methods and a critical evaluation of accuracy, Glob. Change Biol., 2, 169-182, 1996.

Grant, R. H., Heisler, G. M., and Gao, W.: Photosynthetically-active radiation: sky radiance distributions under clear and overcast conditions, Agr. Forest Meteorol., 82, 267-292, 1996.

Grelle, A.: Long-term water and carbon dioxide fluxes from a boreal forest, Ph.D. thesis, Swedish University of Agricultural Sciences, Uppsala, 1997.

Grelle, A. and Lindroth, A.: Eddy-correlation system for longterm monitoring of fluxes of heat, water vapour and $\mathrm{CO}_{2}$, Glob. Change Biol., 2, 297-307, 1996.

Grelle, A., Lindroth, A., and Mölder, M.: Seasonal variation of boreal forest surface conductance and evaporation, Agr. Forest Meteorol., 98-99, 563-578, 1999.

Håkansson, J., and Körling, A.: Upskattning av mängden kol i trädform - en metodstudie, Tech. rep., Dept. of Physical Geography, Lund University, 2002 (in Swedish).

Han, S.-J., Lin, L.-S., Yu, G.-R., Zhang, J.-H., Wu, J.-B., Zho, X.S., and Guan, D.-X.: Dynamics of profiles and storage of carbon dioxide in broad-leaved/Korean forest in Changbai Mountain, J. Forest. Res.-Jpn., 14, 275-279, 2003.

Harrison, A. W. and Coombes, C. A.: Angular distribution of clear sky short wavelength radiance, Sol. Energy, 40, 57-63, 1988.

Hirose, T. and Werger, M. J. A.: Maximizing daily canopy photosynthesis with respect to the leaf nitrogen allocation pattern in the canopy, Oecologia, 72, 520-526, 1987.

Jansson, P.-E., Cienciala, E., Grelle, A., Kellner, E., Lindahl, A., and Lundblad, M.: Simulated evapotranspiration from the Norunda forest stand during the growing season of a dry year, Agr. Forest Meteorol., 98-99, 621-628, 1999.

Knohl, A. and Baldocchi, D. D.: Effects of diffuse radiation on canopy gas exchange processes in a forest ecosystem, J. Geophys. Res., 113, 1-17, 2008. 
Krinner, G., Viovy, N., de Noblet-Ducoudré, N., Ogée, J., Polcher, J., Friedlingstein, P., Ciais, P., Sitch, S., and Prentice, I. C.: A dynamic global vegetation model for studies of the coupled atmosphere-biosphere system, Global Biogeochem. Cy., 19, GB1015, doi:10.1029/2003GB002199, 2005.

Lagergren, F. and Lindroth, A.: Transpiration response to soil moisture in pine and spruce trees in Sweden, Agr. Forest Meteorol., 112, 67-85, 2002.

Law, B. E., Falge, E., Gu, L., Baldocchi, D. D., Bakwin, P., Berbigier, P., Davis, K., Dolman, A. J., Falk, M., Fuentes, J. D., Goldstein, A., Granier, A., Grelle, A., Hollinger, D., Janssens, I. A., Jarvis, P., Jensen, N. O., Katul, G., Mahli, Y., Matteucci, G., Meyers, T., Monson, R., Munger, W., Oechel, W., Olson, R., Pilegaard, K., Paw U, K. T., Thorgeirsson, H., Valentini, R., Verma, S., Vesala, T., Wilson, K., and Wofsy, S.: Environmental controls over carbon dioxide and water vapor exchange of terrestrial vegetation, Agr. Forest Meteorol., 113, 97-120, 2002.

Leuning, R.: Modelling stomatal behaviour and photosynthesis of Eucalyptus grandis, Aust. J. Plant Physiol., 17, 159-175, 1990.

Leuning, R.: A critical appraisal of a combined stomatalphotosynthesis model for $\mathrm{C}_{3}$ plants, Plant Cell Environ., 18, 339355, 1995.

Leuning, R., Kelliher, F. M., De Pury, D. G. G., and Schulze, E. D.: Leaf nitrogen, photosynthesis, conductance and transpiration: scaling from leaves to canopies, Plant, Cell and Environment, 18, 1183-1200, 1995.

Lloyd, J. and Taylor, J. A.: On the temperature dependence of soil respiration, Funct. Ecol., 8, 315-323, 1994.

Lundin, L.-C., Halldin, S., Lindroth, A., Cienciala, E., Grelle, A., Hjelm, P., Kellner, E., Lundberg, A., Mölder, M., Morén, A.-S., Nord, T., Seibert, J., and Stähli, M.: Continuous long-term measurements of soil-plant-atmosphere variables at a forest site, Agr. Forest Meteorol., 98-99, 53-73, 1999.

Mercado, L. M., Bellouin, N., Sitch, S., Boucher, O., Huntingford, C., Wild, M., and Cox, P. M.: Impact of changes in diffuse radiation on the global land carbon sink., Nature, 458, 10141017, 2009.

Mölder, M., Lindroth, A., and Halldin, S.: Water vapor, $\mathrm{CO}_{2}$, and temperature profiles in and above a Forest - Accuracy assessment of an unattended measurement system, J. Atmos. Ocean. Tech., 17, 417-425, 2000.

Monteith, J. L.: Light Distribution and Photosynthesis in Field Crops, Ann. Bot.-London, 29, 17-37, 1965.

Monteith, J. and Unsworth, M.: Principles of Environmental Physics, Edward Arnold, London, 2nd Edn., 1990.

Morén, A.-S., Lindroth, A., Flower-Ellis, J., Cienciala, E., and Mölder, M.: Branch transpiration of pine and spruce scaled to tree and canopy using needle biomass distributions, Trees, 14, 384-397, 2000.

Norman, J. M.: Radiative transfer in vegetation, in: Heat and Mass Transfer in the Biosphere: 1. Transfer Processes in Plant Environment, edited by: de Vries, D. A. and Afgan, N. H., 187-205, John Wiley and Sons, New York, 1975.

Norman, J. M., Miller, E. E., and Tanner, C. B.: Light intensity and sunfleck-size distributions in plant canopies, Agron. J., 63, 743748,1971

Op de Beeck, M., Gielen, B., Jonckheere, I., Samson, R., Janssens, I. A., and Ceulemans, R.: Needle age-related and sea- sonal photosynthetic capacity variation is negligible for modelling yearly gas exchange of a sparse temperate Scots pine forest, Biogeosciences, 7, 199-215, doi:10.5194/bg-7-199-2010, 2010.

Reichstein, M., Falge, E., Baldocchi, D., Papale, D., Aubinet, M., Berbigier, P., Bernhofer, C., Buchmann, N., Gilmanov, T., Granier, A., Grunwald, T., Havrankova, K., Ilvesniemi, H., Janous, D., Knohl, A., Laurila, T., Lohila, A., Loustau, D., Matteucci, G., Meyers, T., Miglietta, F., Ourcival, J.-M., Pumpanen, J., Rambal, S., Rotenberg, E., Sanz, M., Tenhunen, J., Seufert, G., Vaccari, F., Vesala, T., Yakir, D., and Valentini, R.: On the separation of net ecosystem exchange into assimilation and ecosystem respiration: review and improved algorithm, Glob. Change Biol., 11, 1424-1439, 2005.

Roderick, M. L., Farquhar, G. D., Berry, S. L., and Noble, I. R.: On the direct effect of clouds and atmospheric particles on the productivity and structure of vegetation, Oecologia, 129, 21-30, 2001.

Ross, J.: Radiative transfer in plant communities, in: Vegetation and the Atmosphere, Volume 1: Principles, edited by: Monteith, J., Academic Press, London, 13-55, 1975.

Ross, J.: The Radiation Regime and Architecture of Plant Stands, Dr W Junk Publishers, The Hague, 1981.

Sato, H., Itoh, A., and Kohyama, T.: SEIB-DGVM: A new Dynamic Global Vegetation Model using a spatially explicit individualbased approach, Ecol. Model., 200, 279-307, 2007.

Sellers, P., Berry, J., Collatz, G., Field, C., and Hall, F.: Canopy reflectance, photosynthesis, and transpiration, III. A reanalysis using improved leaf models and a new canopy integration scheme, Remote Sens. Environ., 42, 187-216, 1992.

Sinclair, T. R., Murphy, C. E., and Knoerr, K. R.: Development and evaluation of simplified models for simulating canopy photosynthesis and transpiration, J. Appl. Ecol., 13, 813-829, 1976.

Sitch, S., Smith, B., Prentice, I. C., Arneth, A., Bondeau, A., Cramer, W., Kaplan, J. O., Levis, S., Lucht, W., Sykes, M. T., Thonicke, K., and Venevsky, S.: Evaluation of ecosystem dynamics, plant geography and terrestrial carbon cycling in the LPJ dynamic global vegetation model, Glob. Change Biol., 9, 161-185, 2003.

Spitters, C.: Separating the diffuse and direct component of global radiation and its implications for modeling canopy photosynthesis - Part II: Calculation of canopy photosynthesis., Agr. Forest Meteorol., 38, 231-242, 1986.

Spitters, C., Toussaint, H., and Goudriaan, J.: Separating the diffuse and direct component of global radiation and its implications for modeling canopy photosynthesis - Part I: Components of incoming radiation, Agr. Forest Meteorol., 38, 217-229, 1986.

Thum, T., Aalto, T., Laurila, T., Aurela, M., Kolari, P., and Hari, P.: Parametrization of two photosynthesis models at the canopy scale in a northern boreal Scots pine forest, Tellus B, 59, 874890, 2007.

Thum, T., Aalto, T., Laurila, T., Aurela, M., Lindroth, A., and Vesala, T.: Assessing seasonality of biochemical $\mathrm{CO}_{2}$ exchange model parameters from micrometeorological flux observations at boreal coniferous forest, Biogeosciences, 5, 1625-1639, doi:10.5194/bg-5-1625-2008, 2008. 
Urban, O., Janous, D., Acosta, M., Czerný, R., Marková, I., Navrátil, M., Pavelka, M., Pokorný, R., Sprtová, M., Zhang, R., Spunda, V., Grace, J., and Marek, M. V.: Ecophysiological controls over the net ecosystem exchange of mountain spruce stand, Comparison of the response in direct vs. diffuse solar radiation, Glob. Change Biol., 13, 157-168, 2007.

Urban, O., Klem, K., Ač, A., Havránková, K., Holišová, P., Navrátil, M., Zitová, M., Kozlová, K., Pokorný, R., Šprtová, M., Tomášková, I., Špunda, V., and Grace, J.: Impact of clear and cloudy sky conditions on the vertical distribution of photosynthetic $\mathrm{CO}_{2}$ uptake within a spruce canopy, Funct. Ecol., 26, 46$55,2012$.
Von Caemmerer, S.: Biochemical models of leaf photosynthesis, CSIRO Publishing, Collingwood, 2000.

Woodward, F. I. and Lomas, M. R.: Vegetation dynamics - simulating responses to climatic change, Biol. Rev., 79, 643-670, 2004.

Wullschleger, S. D.: Biochemical limitations to carbon assimilation in $C_{3}$ plants - a retrospective analysis of the $A / C_{i}$ curves from 109 species, J. Exp. Bot., 44, 907-920, 1993.

Zaehle, S. and Friend, A. D.: Carbon and nitrogen cycle dynamics in the O-CN land surface model: 1. Model description, site-scale evaluation, and sensitivity to parameter estimates, Global Biogeochem. Cy., 24, GB1005, doi:10.1029/2009GB003521, 2010. 